\title{
OS TRAÇOS CARACTERÍSTICOS DO ANEXO 1 DO PROTOCOLO SOBRE FINANÇAS E INVESTIMENTOS DA COMUNIDADE PARA O DESENVOLVIMENTO DA ÁFRICA AUSTRAL (SADC) ${ }^{1}$
}

\author{
GILLES CISTAC \\ Professor Catedrático da Faculdade de Direito \\ da Universidade Eduardo Mondlane \\ Advogado \\ gilles.cistac@uem.mz
}

\begin{abstract}
Durante a Cimeira dos Chefes de Estado e de Governo que teve lugar em Maseru, Lesoto, no dia 18 de Agosto de 2006, foi firmado o Protocolo sobre Finanças e Investimentos da Região da Comunidade para o Desenvolvimento da África Austral SADC (abreviadamente: o Protocolo). Este acordo é o resultado de um processo que iniciou em 1995 quando a República de África do Sul, como novo membro da Comunidade de Desenvolvimento da África Austral (a seguir designada pela sua sigla inglesa SADC), tornou Estado anfitrião da Unidade de Coordenação do Sector de Finanças e Investimentos, ao qual foi pedido para elaborar o Projecto de Protocolo sobre Finanças e Investimentos. O primeiro Ante-projecto do Protocolo sobre Finanças e Investimentos, de 1994, foi considerado como demasiado sofisticado e foi rejeitado pelos Estados Membros. Contrariamente à metodologia utilizada para a elaboração do Protocolo sobre as Trocas Comerciais - "top-down development process" - foi a do "bottom-up approach" que foi escolhida envolvendo vários parceiros oriundos do sector público e privado. Assim, uma aproximação consensual permitiu construir vários consensos nos respectivos sectores. Nas fases subsequentes, um conjunto de Memoranda of Understandings (MOUs), cobrindo as áreas chaves da integração económica foram elaborados. Na fase final, esses memorandos subsumiram num
\end{abstract}

\footnotetext{
${ }^{1}$ Comunicación presentada en el Seminario del Departamento de Derecho de la Universidad de Almería, dirigido por MARÍA JOSÉ CAZORLA GONZÁLEZ, el dia 14 de Enero de 2013.
} 
Protocolo como os seus anexos (11 anexos) e constituem, ao mesmo tempo, as bases substantivas do Protocolo. O Protocolo entrou em vigor no dia 16 de Abril de 2010. O

Protocolo pode ser considerado como um verdadeiro instrumento de política económica que tem como função, por um lado, de influenciar ao nível macroeconómico o volume dos investimentos na SADC, e, por outro, ao nível individual de orientá-los em funções dos objectivos económicos especificados no próprio Protocolo. O presente estudo tem por objecto apenas o Anexo 1 do Protocolo, isto é, o relativo a "Cooperação na Área de Investimento"; que é o mais relevante para o investidor. Nesta perspectiva, como apresentar o conteúdo deste Anexo? Uma primeira abordagem é de optar para uma aproximação analítica e descrever e apresentar os principais itens consagrados neste documento. Assim, poderia se apresentar a definição, e admissão do investimento estrangeiros tais como foram desenvolvidos no Anexo 1 bem como as disposições relativas ao repatriamento de investimentos e retornos, a sua garantia e os modos de resolução de litígios. Contudo, não é esta via que será privilegiada nesta apresentação. É a metodologia sistémica que será utilizada para analisar o Anexo 1 do referido Protocolo. Nesta perspectiva, a de pensar o Anexo 1 e o Protocolo como sistemas, a questão essencial é: quais são os traços característicos do sistema instituído pelo Anexo 1 do Protocolo? O primeiro traço é a afirmação e preservação da competência exclusiva do Estado Acolhedor em matéria de determinação do regime jurídico do investimento estrangeiro; o segundo, que de alguma forma tenta moderar o primeiro e cria, de facto a dinâmica do sistema, é consagração de algumas inflexões à competência exclusiva do Estado Acolhedor por limites e recomendações.

KEYWORDS: Finanças e Investimentos, Trocas Comerciais 


\section{INTRODUÇÃO}

Durante a Cimeira dos Chefes de Estado e de Governo que teve lugar em Maseru, Lesoto, no dia 18 de Agosto de 2006, foi firmado o Protocolo sobre Finanças e Investimentos da Região da Comunidade para o Desenvolvimento da África Austral $S A D C^{2}$ (abreviadamente: o Protocolo) ${ }^{3}$. Este acordo é o resultado de um processo que iniciou em 1995 quando a República de África do Sul, como novo membro da Comunidade de Desenvolvimento da África Austral (a seguir designada pela sua sigla inglesa $\mathrm{SADC}^{4}$ ), tornou Estado anfitrião da Unidade de Coordenação do Sector de Finanças e Investimentos, ao qual foi pedido para elaborar o Projecto de Protocolo sobre Finanças e Investimentos ${ }^{5}$ com “... the rationale of ensuring comprehensiveness of a SADC specific approach, but also adequate responsiveness to international trends and developments in this sector, a wide amount of research has been undertaken from the beginning of the 1990s onwards to inform the process " ${ }^{\text {. O }}$ primeiro Ante-projecto do Protocolo sobre Finanças e Investimentos, de 1994, foi considerado como demasiado sofisticado e foi rejeitado pelos Estados Membros “.... as it required a more advanced

\footnotetext{
${ }^{2}$ Moçambique ratificou o Protocolo em 2007 - Resolução n. ${ }^{\circ}$ 44/2007: Ratifica o Protocolo sobre Finanças e Investimentos da Região da Comunidade para o Desenvolvimento da África Austral SADC, B.R., 6 de Dezembro de 2007, Suplemento, I Série - N. ${ }^{\circ} 4$. ${ }^{3}$ RUF, Yvonne, "The SADC Protocol on finance and investment: background, implications and prospects
for deepening regional financial integration in SADC", Monitoring Regional Integration in Southern
Africa, Vol. 6, 2006, p. 211 .
${ }^{4}$ Sobre a SADC, vide, OOSTHUIZEN, H. Gabriël, The Southern African Development Community. The
organization, its policies and prospects, Midrand, South Africa, Institute for Global Dialogue, 2006, 402
p.; MACHAVA, Almeida Zacharias, Free Trade and Regional Integration in a Globalized World: The
Case of Southern Africa Development Community and its Impact in Mozambique, University of Macau,
Macau, 2008, 137 p.; MACHAVA, Almeida Zacharias, "SADC, uma "Pseudo-Integração" Regional a
caminho da União Aduaneira", Revista "Temas de Integração", $1 .^{\circ}$ e $2 .^{\circ}$ Semestres de 2010, n. ${ }^{\circ} 29$ e 30 ,
pp. 233-252; MASSANGAIE, Arnaldo Timóteo, O Processo de Integração Regional na SADC.
Perspectivas de Desenvolvimento Económico e Cooperação Política, Instituto Superior de Relações
Internacionais, Mestrado em Relações Internacionais e Desenvolvimento. Especialização em Comércio e
Finanças Internacionais, Maputo, 2013, $107 \mathrm{p}$. Sobre o potencial da Região, vide, SADC, Major
Achievements and Challenges, Gaborone, SADC, Published, 2005, p. 9ss.

${ }^{5}$ RUF, Yvonne, "The SADC Protocol on finance and investment: background, implications and prospects for deepening regional financial integration in SADC", op. cit., p. 211.

${ }^{6}$ Idem, p. 216.
} 
stage of economic integration with strong and effective institutional mechanisms for the benefits to materialise; preconditions which did not exist in SADC then"7. Contrariamente à metodologia utilizada para a elaboração do Protocolo sobre as Trocas Comerciais - "top-down development process" - foi a do "bottom-up approach" que foi escolhida envolvendo vários parceiros oriundos do sector público e privado. Assim, uma aproximação consensual permitiu construir vários consensos nos respectivos sectores $^{8}$. Nas fases subsequentes, um conjunto de Memoranda of Understandings (MOUs), cobrindo as áreas chaves da integração económica foram elaborados. Na fase final, esses memorandos subsumiram num Protocolo com os seus anexos (11 anexos $\left.{ }^{9}\right)$ e constituem, ao mesmo tempo, as bases substantivas do Protocolo ${ }^{10}$. O Protocolo entrou em vigor no dia 16 de Abril de $2010^{11}$.

O Protocolo pode ser considerado como um verdadeiro instrumento de política económica que tem como função, por um lado, de influenciar, ao nível macroeconómico, o volume dos investimentos na SADC, e, por outro, ao nível individual, de orientá-los em funções dos objectivos económicos especificados no próprio Protocolo; como refere YVONNE RUTH: “The overall goal is to create an environment conducive to attracting intra - and extra - SADC investment flows and to

\footnotetext{
${ }^{7}$ Id., ibid.

${ }^{8}$ Id., ibid.

${ }^{9}$ ANEXO 1 - Cooperação na Área de Investimento; ANEXO 2 - Convergência macroeconómica; ANEXO 3 - Cooperação em tributação e questões conexas; ANEXO 4 - Cooperação e coordenação de políticas de controlo cambial; ANEXO 5 - Harmonização dos quadros jurídicos e operacionais dos bancos centrais; ANEXO 6 - Cooperação nos Sistemas de Pagamento, Compensação e Liquidação; ANEXO 7 - Cooperação entre os Bancos Centrais na Área de Tecnologias de Informação e Comunicação; ANEXO 8 - Cooperação e Coordenação da Regulação e Supervisão Bancárias; ANEXO 9 - Cooperação no Âmbito das Instituições de Financiamento ao Desenvolvimento; ANEXO 10 Cooperação no Domínio das Instituições e Serviços Não-Bancários; ANEXO 11 - Comité de Bolsas de Valores da SADC. De acordo com o n. ${ }^{\circ} 3$ do Artigo 2 do Protocolo: "Cada um dos anexos constitui uma parte integrante do presente Protocolo ...".
}

10 SADC, Finance \& Investment Protocol. Information Brochure. Disponível em: $<$ http://www.sadc.int/cms/uploads/SADC\%20Finance\%20and\%20Investment\%20Protocol\%20Brochure \%20-\%20English.pdf>. Acesso em: 29-10-2012, p. 9.

11 VAN ROESSEL, Hannah, "The SADC Protocol on Finance and Investments: summary of a comparison with Bilateral Investments Treaties", tralac Paper. Disponível em: http://www.tralac.org/wpcontent/blogs.dir/12/files/2011/uploads/SADC_FIP_Summary_8March2011.pdf>. Acesso em: 29-092012. 
achieve and maintain macroeconomic stability and convergence among SADC countries" ${ }^{\prime 2}$.

O presente estudo tem por objecto apenas o Anexo 1 do Protocolo, isto é, o relativo a "Cooperação na Área de Investimento"; que é o mais relevante para o investidor. Nesta perspectiva, como apresentar o conteúdo deste Anexo? Uma primeira abordagem é de optar para uma aproximação analítica e descrever e apresentar os principais itens consagrados neste documento. Assim, poderia se apresentar a definição, e admissão do investimento estrangeiros tais como foram desenvolvidos no Anexo 1 bem como as disposições relativas ao repatriamento de investimentos e retornos, a sua garantia e os modos de resolução de litígios ${ }^{13}$. Contudo, não é esta via que será privilegiada nesta apresentação. É a metodologia sistémica que será utilizada para analisar o Anexo 1 do referido Protocolo. Nesta perspectiva, a de pensar o Anexo 1 e o Protocolo como sistemas, a questão essencial é: quais são os traços característicos do sistema instituído pelo Anexo 1 do Protocolo? O primeiro traço é a afirmação e preservação da competência exclusiva do Estado Acolhedor ${ }^{14}$ em matéria de determinação do regime jurídico do investimento estrangeiro (I); o segundo, que de alguma forma tenta moderar o primeiro e cria, de facto a dinâmica do sistema, é a consagração de algumas inflexões à competência exclusiva do Estado Acolhedor por limites e recomendações (II).

\section{A AFIRMAÇÃO DA COMPETÊNCIA EXCLUSIVA DO ESTADO ACOLHEDOR EM MATÉRIA DE DETERMINAÇÃO DO REGIME JURÍDICO DO INVESTIMENTO ESTRANGEIRO}

\footnotetext{
12 RUF, Yvonne, "The SADC Protocol on finance and investment: background, implications and prospects for deepening regional financial integration in SADC”, op. cit., p. 211.

${ }^{13}$ É esta metodologia que o autor utilizou para apresentar o Protocolo sobre Finanças e Investimentos da Região da Comunidade para o Desenvolvimento da África Austral - SADC na Conferência de Macau em Novembro de 2012 subordinada ao tema: Fórum sobre Questões contemporâneas relativas ao Comércio e Investimento China África.

${ }^{14}$ De acordo com o n. ${ }^{\circ} 2$ do Artigo 1 do Anexo 1, "Estado acolhedor" significa: “... Estado Parte da SADC em cujo território o investimento é feito ou está localizado".
} 
Como se afirma esta competência exclusiva do Estado Acolhedor em matéria de determinação do regime jurídico do investimento no Anexo 1? (A); e qual é a sua justificação? (B), constituirão as duas perguntas que articularam a primeira parte desta comunicação.

\section{A. As manifestações da competência exclusiva do Estado Acolhedor em matéria de} determinação do regime jurídico do investimento no Anexo 1

As manifestações da competência exclusiva do Estado Acolhedor em matéria de determinação do regime jurídico do investimento estrangeiro no Anexo 1 são numerosas. Apresentar-se-á as principais que se articulam em torno da definição do investimento (a), da sua admissão (b), da sua promoção (c) e do seu repatriamento (d). Além disso, duas situações manifestam, também, esta competência exclusiva, são as do recrutamento de pessoal sujeito às normas internas do Estado Acolhedor (e) e o acesso aos meios alternativos de resolução de conflitos (f).

\section{a) A definição do investimento}

Apesar do facto de o n. ${ }^{\circ} 2$ do Artigo 1 do Anexo 1 definir o "investimento"15, isto significa que o Anexo 1 consagra uma definição convencional do "investimento" que determina o objecto do Anexo 1 do Protocolo e, ao mesmo tempo, o seu âmbito de aplicação -, cada Estado Parte do Protocolo admite o investimento no seu território “... de acordo com as suas legislações e normas internas" (n. ${ }^{\circ} 1$ do Artigo 2 do Anexo 1). Consequentemente, não são todos os “activos de investimentos" abstractamente

\footnotetext{
${ }^{15}$ Nos termos do n. ${ }^{\circ} 2$ do Artigo 1 do Anexo 1, "Investimento significa a compra, aquisição ou estabelecimento de todo tipo de activos de investimentos que contribuem para a capacidade de produção de um Estado Acolhedor, e em particular inclui, mas não exclusivamente:

a) Propriedade de bens móveis e imóveis e quaisquer outros direitos de propriedade, como hipotecas, penhores ou compromissos;

b) Acções, cotas e obrigações societárias ou participação na propriedade das referidas sociedades;

c) Títulos de crédito ou qualquer rendimento ao abrigo de contrato com valor financeiro e empréstimos;

d) Direitos de autor, direitos de propriedade relativos a conhecimentos e direitos incorpóreos e de propriedade industrial, tais como patentes por invenções, denominações comerciais, desenhos ou modelos industriais, marcas de fábrica e comerciais;

e) Direitos conferidos em conformidade com a lei ou ao abrigo de um contrato, incluindo as concessões para pesquisa, cultivo, extracção ou exploração de recursos naturais”.
} 


\section{Doctrina y Jurisprudencia}

definidos que serão considerados como "investimentos", mas apenas aqueles bens, direitos e interesses que serão qualificados como tal pela legislação interna do Estado Acolhedor. Do mesmo modo, de acordo com a definição da palavra "investimento" no n. ${ }^{\circ} 2$ do Artigo 1 do Anexo 1 do Protocolo: "Investimento significa a compra, aquisição ou estabelecimento de todo tipo de activos de investimentos que contribuem para a capacidade de produção de um Estado Acolhedor ...” (o sublinhado é nosso). Por outras palavras, são apenas os "activos de investimentos" que o Estado Acolhedor considera como propícios para a promoção do desenvolvimento da economia nacional ("que contribuem para a capacidade de produção") que serão considerados como "Investimentos" por este Estado. Esta situação é bastante comum em várias convenções bilaterais sobre a promoção e protecção do investimento ${ }^{16}$. Pois, o Anexo 1 consagra "um aspecto finalístico do investimento", 17 , para parafrasear JEAN-PIERRE LAVIEC, que funda-se num critério subjectivo porque depende da concepção nacional do desenvolvimento económico ou seja, do Estado Acolhedor do investimento, por um lado, e dos meios a implementar para concretizá-lo, por outro. Isto conduz a considerar que pode ocorrer situações em que, um determinado bem ou direito pode ser qualificado de "investimento" por um Estado e, considerado num sentido oposto por um outro Estado, ambas as partes no mesmo Protocolo. Esta técnica selectiva da definição do investimento no sentido de apenas considerar como "investimentos" aqueles que contribuem para a capacidade de produção do Estado Acolhedor tem por principal objectivo, desenvolver algumas actividades e, eventualmente, restringir outras. Neste sentido, os Estados Partes podem estabelecer algumas condições e alguns limites aos investimentos em proveniência do estrangeiro. Alguns métodos utilizados consistem, em particular, em institucionalizar procedimentos de autorização administrativa ${ }^{18}$ desses que lhes permitem agir directamente sobre o volume e as condições de investimento correspondente a suas necessidades e aos seus objectivos de política económica. Assim, esta técnica permite influenciar as condições de gestão das empresas, o seu regime fiscal, a concessão de créditos, a sua evolução tecnológica ou o volume do emprego.

\footnotetext{
${ }^{16}$ LAVIEC, Jean-Pierre, Protection et promotion des investissements. Étude de droit international économique, col. "Publications de l'Institut Universitaire de Hautes Études Internationales, Genève", Paris, PUF, 1985, p. 19.

${ }^{17}$ Id., ibid.

${ }^{18}$ É o caso, por exemplo, no ordenamento jurídico moçambicano.
} 
Esta faculdade reconhecida pelo Protocolo a um Estado Parte de definir, ele próprio, o que é um investimento permite, concretamente, preservar o seu poder de decisão. Ela constitui uma expressão da sua vontade, e da sua soberania o que é, de alguma forma, muito lógico, tomando em conta a natureza da SADC que é, ainda hoje, uma organização regional que não ultrapassou o estado da cooperação interestadual ${ }^{19}$. Consequentemente, deve admitir-se que a noção de "Investimento" não engloba todos os bens e direitos dos estrangeiros, mas apenas uma parte dentre deles.

\section{b) A admissão do investimento}

$\mathrm{O}$ n. ${ }^{\circ} 1$ do Artigo 2 do Anexo 1 dispõe que cada Estado Parte admite os investimentos de acordo com a sua legislação interna (leis e regulamentos). Esta disposição tem, pelo menos, duas consequências. Em primeiro lugar, esta atribuição de competência exclusiva ao Estado Parte implica que o âmbito de aplicação do Protocolo abrange apenas os investimentos que satisfizeram as condições fixadas pela legislação do Estado Acolhedor. Em segundo lugar, a referida disposição reconhece explicitamente o direito de cada Estado Parte de admitir ou não admitir investimentos sobre o seu território $^{20}$. Assim, o regime consagrado é o da livre decisão do Estado Acolhedor ${ }^{21}$. O reconhecimento do direito do Estado de admitir ou não investimentos estrangeiros no seu território foi fortemente contestado nas bases de política económica ${ }^{22}$. Todavia, a maior parte dos estudos económicos sobre esta questão demonstram que o Estado Acolhedor tem toda a legitimidade para exercer um controlo e estabelecer condições para a admissão de investimentos estrangeiros; como refere JEAN-PIERRE LAVIEC:

\footnotetext{
${ }^{19}$ Sobre esses aspectos, vide, CISTAC, Gilles, "Os problemas da integração jurídica na Comunidade de Desenvolvimento da África Austral”, em, CISTAC, Gilles, Aspectos Jurídicos da Integração Regional, Maputo, Escolar Editora, 2012, p. 225ss.

${ }^{20}$ O Anexo 1 define expressamente o termo "Território" como “... o total da superfície terrestre de um Estado Parte, e, em relação a um Estado Parte litoral, inclui o mar territorial e qualquer superfície marítima adjacente ao limite exterior do mar territorial do referido Estado Parte litoral, que terá sido ou será designado no futuro, ao abrigo da legislação interna daquele Estado Parte litoral, de acordo com o direito internacional, como uma área dentro do qual o Estado Parte litoral poderá exercer os direitos relativos ao fundo do mar e ao subsolo, assim como aos recursos naturais” (Artigo 1).

${ }^{21}$ Este regime encontra-se consagrado na maior parte das convenções bilaterais sobre a protecção e a promoção dos investimentos, vide, LAVIEC, Jean-Pierre, op. cit., p. 54.

${ }^{22}$ Idem, p. 60.
} 


\section{Doctrina y Jurisprudencia}

"Par là il est possible d'améliorer le quotient avantage-coût au bénéfice de l'économie nationale, et d'éviter que des coûts disproportionnés par rapport aux avantages ne soient encourus ${ }^{, 23}$.

\section{c) A promoção do investimento}

A erradicação da pobreza, que constitui uma "Área de Intervenção Transversais" de carácter prioritário na $\mathrm{SADC}^{24}$, passa, entre outros, pela promoção do investimento, de forma a estimular o crescimento económico e a criação de oportunidades de emprego para os pobres ${ }^{25}$. Em várias ocasiões, o RISDP insistiu sobre a “... preservação dum ambiente favorável ao investimento nacional e estrangeiro",26 que constitui um objectivo estratégico ${ }^{27}$.

A noção de promoção de investimentos visa, em particular, alguns aspectos das legislações internas sobre os investimentos, que obstaculizam a admissão dos investimentos internacionais e que concedem vantagens/ou benefícios aos investidores estrangeiros $^{28}$. Em todo caso, deve-se admitir que o objectivo da promoção de investimentos é de facilitar as relações de investimento, reduzindo alguns obstáculos e estimulando a vinda de investimentos estrangeiros através de benefícios. É, em particular, os princípios estruturantes das legislações internas que consagraram medidas visando a promover o investimento estrangeiro ${ }^{29}$. Um debate recente, em Moçambique, questionou o interesse das isenções fiscais concedidas para o Estado aos grandes projectos de investimentos como a MOZAL e a SASOL. Alguns economistas, em

\footnotetext{
${ }^{23}$ Idem, p. 63.

${ }^{24}$ Plano Estratégico Indicativo de Desenvolvimento Regional (RISDP), 4.2. Este documento pode ser consultado no site da SADC. Disponível em: < http://www.sadc.int/key documents/risdp/index.php>.

${ }^{25}$ RISDP, 4.2.4.

${ }^{26}$ RISDP, 3.2.3.2.

${ }^{27}$ CISTAC, Gilles, "Contribuição para a elaboração de uma estratégia para a harmonização do Direito Económico e Comercial na SADC”, em, CISTAC, Gilles, Aspectos Jurídicos da Integração Regional, op. cit., p. 37.

${ }^{28}$ LAVIEC, Jean-Pierre, Protection et promotion des investissements. Étude de droit international économique, op. cit., pp. 73-74.

${ }^{29}$ Vide, por exemplo, em Moçambique, a Lei n. ${ }^{\circ}$ 4/2009: Aprova o Código dos Benefícios Fiscais, B.R., 12 de Janeiro de $2009,3 .^{\circ}$ Suplemento, I Série - N. ${ }^{\circ} 1$.
} 


\section{Doctrina y Jurisprudencia}

particular, demonstraram que se apenas a MOZAL (fundição de alumínio para exportação) e a SASOL (extracção de gás para exportação) não tivessem isenção físcal, teriam canalizado ao Orçamento do Estado 100 milhões de dólares/ano entre 2004 e 2010. Os benefícios fiscais aos grandes projectos são superiores ao investimento na agricultura e nas pequenas e médias empresas o que pressionou o Governo a renegociar o conjunto dos contratos com os "mega-projectos" $" 30$.

Do mesmo modo do que se encontra estabelecido nos acordos internacionais de investimento da Associação de cooperação Asia-Pacífico ${ }^{31}$, não existe uma disposição expressa que promove directamente e, em termos substanciais, os fluxos de investimentos estrangeiros. Aqui, também, existe uma competência exclusiva do Estado Acolhedor no que concerne os mecanismos de promoção de investimentos que ele considera como oportunos; como refere o n. ${ }^{\circ} 1$ do Artigo 2 do Anexo 1 do Protocolo, “Cada Estado Parte promoverá os investimentos ...”. Do mesmo modo, se o n. 2 do Artigo 2 do Anexo 1 estabelece que: "O Estado Acolhedor facilitará e criará condições favoráveis aos investimentos no seu território através de medidas administrativas apropriadas ...”, as referidas medidas são tomadas “... de acordo com as suas legislações e normas internas”. Face a esta situação que já foi encontrada, anteriormente, a promoção estabelecida no Anexo 1, apenas podia ser indirecta.

\section{d) $\mathrm{O}$ repatriamento de investimentos e de retornos}

O Anexo 1 do Protocolo integra, em particular, uma cláusula regulando a transferência de investimentos e retornos (Artigo 9). A referida disposição, ao contrário do que pode se encontrar em outros instrumentos internacionais ${ }^{32}$, não é detalhada; apenas uma frase: "Cada Estado Parte garantirá aos investidores as facilidades em termos de repatriamento de investimentos e de retornos, em conformidade com as normas e os regulamentos estipulados pelo Estado Acolhedor". De jure, o Artigo 9 do

\footnotetext{
${ }^{30}$ Jornal, O País, 8/06/2012.

${ }^{31} \mathrm{CNUCED}$, Identification des aspects essentiels des accords d'investissement dans la région de l'APEC, Nations Unies, New York et Genève, 2008, p. xiii.

${ }^{32}$ Vide, por exemplo, o Artigo 5 do Artigo do Tratado entre a República de Moçambique e os Estados Unidos de América sobre a Promoção e Protecção Recíproca de Investimentos; Artigo 6 do Acordo sobre a Promoção e Protecção Recíproca de Investimento entre o Governo da República de Moçambique e o Governo da República da China.
} 
Anexo 1 procede a um reenvio, a título principal, ao direito interno do Estado importador de investimento Com efeito, o Artigo 9 do Anexo 1 consagra o reenvio, a título principal, ao direito interno do Estado importador de investimento no que concerne o regime jurídico das transferências. O referido artigo não parece restringir explicitamente o direito do Estado Acolhedor. Com efeito, a referida disposição não estabelece ou impõe um "princípio de livre transferência" com se pode encontrar em algumas convenções bilaterais sobre a promoção e protecção recíproca de investimentos ${ }^{33}$. Essas "facilidades" - termo despropositadamente vago - que constam do referido artigo, deixa o direito do Estado Acolhedor regular o regime do "repatriamento de investimentos e de retornos" sem verdadeiros constrangimentos ou limites. Esta competência do direito interno do Estado Acolhedor parece, também, total no sentido de que não distingue entre o conteúdo da transferência - por exemplo, entre transferências de capital e transferências de lucros ou dividendos. Assim, deve-se deduzir que o Estado Acolhedor é livre de aplicar a sua legislação, lato sensu, às transferências - "repatriamento de investimentos e de retornos" - tão restritiva é, e tão instável é s4. $^{34}$.

\footnotetext{
${ }^{33}$ LAVIEC, Jean-Pierre, op. cit., p. 121ss.

${ }^{34}$ No ordenamento jurídico moçambicano, o regime jurídico da "transferência" congrega várias normas jurídicas. O n. ${ }^{\circ} 1$ do Artigo 14 da Lei n. ${ }^{\circ}$ 3/93, de 24 de Junho determina que: "O Estado garante, de acordo com as condições fixadas na respectiva autorização ou outros instrumentos jurídicos pertinentes ao investimento, a transferência para o exterior de ...”. A efectivação das transferências está condicionada ao cumprimento de várias formalidades. A primeira é relativa à comprovação do cumprimento das obrigações fiscais (o documento de quitação comprovativo do cumprimento das obrigações fiscais para efeitos de transferências de lucros, é passado pelo Ministério das Finanças no prazo de trinta dias contados a partir da data da apresentação do respectivo pedido (n. ${ }^{\circ} 2$ do Artigo 15 da Lei n. ${ }^{\circ} 3 / 93$, de 24 de Junho)); a segunda é relativa à posse da autorização do investimento (o documento de quitação comprovativo da realização do investimento para efeitos de transferências de lucros, é passado pelo Ministério das Finanças no prazo de trinta dias contados a partir da data da apresentação do respectivo pedido (n. ${ }^{\circ} 2$ do Artigo 15 da Lei n. ${ }^{\circ} 3 / 93$, de 24 de Junho)) e a terceira diz respeito à observação das formalidades cambiais (As transferências de lucros exportáveis, bem como do capital investido reexportável, processar-se-ão na moeda convertível da opção do investidor, em conformidade com o disposto na lei e respectiva regulamentação e no documento de autorização de cada projecto específico (n. ${ }^{\circ} 4$ do Artigo 15 da Lei n. ${ }^{\circ}$ 3/93, de 24 de Junho). Em particular, o n. 5 do Artigo 6 da Lei n. ${ }^{\circ}$ 11/2009: Regula actos, negócios, transacções e operações de toda a índole, B.R., 11 de Março de 2009, I Série - N. ${ }^{\circ} 10$, considera como "operações de capitais, sujeitas à autorização da autoridade cambial (Banco de Moçambique): “a) investimento directo estrangeiro". Vide, também, Artigo 5 do Decreto n. ${ }^{\circ}$ 83/2010: Aprova o Regulamento da Lei n. ${ }^{\circ}$ 11/2009, de 11 de Março. Lei Cambial e revogadas as normas regulamentares em contrário, B.R., 31 de Dezembro de 2010, $20{ }^{\circ}$ Suplemento, I Série $-\mathrm{N} .^{\circ}$ 52. A realização da transferência de rendimentos de investimento directo estrangeiro não carece de autorização do Banco de Moçambique, estando, porém, sujeita ao registo cambial (n. ${ }^{\circ} 2$ do Artigo 54 e Artigo 55 do Decreto n. ${ }^{\circ} 83 / 2010$, de 31 de Dezembro). A autorização é concedida mediante a emissão de Boletim de Autorização (n. ${ }^{\circ} 3$ do Artigo 64 do Decreto n. ${ }^{\circ}$ 83/2010, de 31 de Dezembro).
} 


\section{e) $O$ recrutamento de pessoal sujeito às normas internas do Estado Acolhedor}

O recrutamento de pessoal, envolvido em projectos de investimentos, está sujeito às normas internas do Estado Acolhedor. Para exercer uma determinada actividade remunerada e permanecer no território de um determinado Estado, regra geral, um estrangeiro deve beneficiar de uma autorização específica lato sensu (por exemplo, visto de trabalho). A concessão desta autorização constitui uma medida de polícia administrativa que é da competência exclusiva do Estado Acolhedor. Neste sentido, o Artigo 11 do Anexo 1 do Protocolo precisa: "Sujeito às suas legislações e aos seus regulamentos internos, os Estados Partes permitirão que os investidores recrutem pessoal chave da sua escolha, independentemente da nacionalidade e de acordo com as seguintes circunstâncias ...”. Em todo caso, trata-se de uma questão sensível em que os interesses legítimos de um Estado Acolhedor e os de um investidor estrangeiro não são necessariamente convergentes ${ }^{35}$. Com efeito, leis nacionais podem conceder a prioridade ou a exclusividade ${ }^{36}$ ao emprego de cidadãos nacionais e

Vide, também, Artigo 25 do AVISO N. ${ }^{\circ}$ 5/GGBM/96, de 19 de Julho de 1996). É de destacar uma restrição à transferência que condiciona o montante desta ao resultado comercial obtido pelo investidor estrangeiro. De acordo com o n. ${ }^{\circ} 6$ do Artigo 15 da Lei n. ${ }^{\circ}$ 3/93, de 24 de Junho: "A transferência de lucros exportáveis, em cada exercício económico, será prontamente assegurada sempre que o saldo positivo em divisas produzido pelo empreendimento ou pelo conjunto de empreendimentos levados a cabo pelo mesmo investidor ou grupo de investidores estrangeiros associados permitir a necessária cobertura". Ainda como afirma o $\mathrm{n} .{ }^{\circ} 7$ do referido artigo: "Verificando-se a insuficiência de fundo cambial para a cobertura dos lucros a exportar em um dado exercício económico por projecto que não produza saldo positivo em moeda externa, o remanescente transitará, para efeitos da sua transferência, para o exercício ou exercícios económicos seguintes". Neste caso, a transferência "... será autorizada e efectuada em condições a acordar com o respectivo investidor estrangeiro" ( $\left.\mathrm{n} .{ }^{\circ} 8\right)$. Como refere JEANPIERRE LAVIEC, trata-se do princípio de “... auto-suficiência em divisas de um investimento estrangeiro", op. cit., p. 127.

${ }^{35}$ LAVIEC, Jean-Pierre, Protection et promotion des investissements. Étude de droit international économique, op. cit., p. 111.

${ }^{36}$ Por exemplo, o n. 3 do Artigo 31 da Lei n. ${ }^{\circ}$ 23/2007, de 1 Agosto (Lei do Trabalho moçambicana) dispõe: "Sem prejuízo do disposto no número anterior, pode o Estado moçambicano reservar exclusivamente a cidadãos nacionais determinadas funções ou actividades que se enquadrem nas restrições ao seu exercício por cidadão estrangeiro, nomeadamente em razão do interesse público". Contudo, sem ser uma exclusividade "a criação de postos de emprego para trabalhadores nacionais e a elevação da qualificação profissional da mão-de-obra moçambicana”, pode constituir um objectivo dos investimentos, vide, alínea d) do Artigo 7 da Lei n. ${ }^{\circ} 3 / 93$, de 24 de Junho. 


\section{Doctrina y Jurisprudencia}

estabelecer, as vezes, exigências quantitativas e ou qualitativas ${ }^{37}$. Por outro lado, um investidor estrangeiro deve poder contratar os técnicos e quadros experimentados que julga competentes para o cumprimento de tarefas de maior complexidade e em lugares de gestão e administração da empresa, mesmo se estes são estrangeiros. Uma parte da vantagem comparativa de um investimento pode residir no saber e saber-fazer gerencial e técnico dos seus trabalhadores estrangeiros ${ }^{38}$.

\section{f) $\mathrm{O}$ condicionamento de acesso aos meios alternativos de resolução de conflitos à regra do esgotamento das vias de recursos nacionais}

No caso de litígios entre o Estado Acolhedor e um investidor, o Anexo 1 do Protocolo prevê duas modalidades de resolução de conflitos: a resolução jurisdicional dos conflitos pelos tribunais do Estado Acolhedor e a resolução regional e transnacional dos conflitos. Contudo, o acesso aos mecanismos não nacionais de resolução de litígios - Tribunal da SADC e arbitragem - está condicionado ao esgotamento das vias de recursos nacionais. De acordo com o n. ${ }^{\circ} 1$ do Artigo 28 do Anexo 1: “Os litígios entre um investidor e um Estado Parte relacionados com obrigações do último no âmbito de um investimento admitido do primeiro, que não forem resolvidos amistosamente e após esgotadas as vias de recursos nacionais, serão submetidos a arbitragem internacional ...” (o sublinhado é nosso). O esgotamento das vias de recursos nacionais é um princípio fundamental de todos os sistemas internacionais de protecção dos Direitos

\footnotetext{
${ }^{37}$ Por exemplo, o n. ${ }^{\circ} 5$ do Artigo 31 da Lei n. ${ }^{\circ}$ 23/2007, de 1 Agosto dispõe: “O empregador, consoante o tipo de classificação de empresa, previsto no artigo 34 da presente Lei, pode ter ao seu serviço trabalhador estrangeiro, mediante comunicação ao Ministro do Trabalho ou a quem este delegar, de acordo com as seguintes quotas:
}

a) cinco por cento da totalidade dos trabalhadores, nas grandes empresas;

b) oito por cento da totalidade dos trabalhadores, nas médias empresas;

c) dez por cento da totalidade dos trabalhadores, nas pequenas empresas".

A grande empresa é a que emprega mais de cem trabalhadores; média empresa é a que emprega mais de dez até ao máximo de cem trabalhadores; pequena empresa é a que emprega até dez trabalhadores (n. ${ }^{\circ} 1$ do Artigo 34 da Lei n. ${ }^{\circ}$ 23/2007, de 1 de Agosto).

${ }^{38}$ CNUCED, Identification des aspects essentiels des accords d'investissement dans la région de l'APEC, op. cit., p. 22. 


\section{Doctrina y Jurisprudencia}

Humanos $^{39}$; como refere FATSAH OUGUERGOUZ: "Esta regra visa essencialmente a

defender a soberania dos Estados; ela é fundamentada no princípio segundo o qual é preciso previamente deixar ao Estado posto em causa a possibilidade de corrigir a situação litigiosa no âmbito do seu ordenamento jurídico interno" ${ }^{, 40}$. Assim, o investidor litigante deve explorar todos os meios jurídicos adequados e eficazes postos a sua disposição pelo sistema jurisdicional, no seu todo, do Estado Acolhedor, para a "reparação de uma injustiça", antes de ter acesso aos mecanismos não nacionais de resolução de conflitos previstos no n. ${ }^{\circ} 2$ do Artigo 28 do Anexo 1. Olhando para o Direito comparado, pode-se verificar que, em algumas circunstâncias, a regra do esgotamento das vias de recursos nacionais pode ser ultrapassada, nomeadamente quando as referidas vias são inexistentes, inacessíveis ou ineficazes ${ }^{41}$.

\section{B. A justificação da competência exclusiva do Estado Acolhedor em matéria de determinação do regime jurídico do investimento}

As características orgânico-estruturais da SADC faz com que esta organização de integração regional ainda está por finalizar (a) e esta situação, de facto, tem repercussões sobre o como deve ser pensado o seu próprio processo de integração, o seu modo de funcionamento e a sua metodologia de tratamento dos seus problemas o que densifica e exemplifica, concretamente, o Anexo 1 do Protocolo (b).

a) A SADC uma organização de integração regional ainda por finalizar

\footnotetext{
${ }^{39}$ Vide, em particular, o Artigo 50 da Carta Africana dos Direitos Humanos e dos Povos.

${ }^{40}$ OUgUERGOUZ, Fatsah, La Charte Africaine des Droits de l'Homme et des Peuples. Une approche juridique des droits de l'Homme entre tradition et modernité, Paris, Presses Universitaires de France, 1993, p. 325. Vide, também, SUDRE, Frédéric, La Convention Européenne des Droits de l'Homme, 2. ${ }^{\text {a }}$ ed., Paris, Presses Universitaires de France, 1992, p. 54.

${ }^{41}$ ETEKA YEMET, Valère, La Charte Africaine des Droits de l'Homme et des Peubles, col. "Logiques Juridiques", Paris, Editions L'Harmattan, 1996, p. 309ss.; ONORIA, Henry, “The African Commission on Human and People's Rights and the exhaustion of local remedies under the African Charter", African Human Rights Law Journal, Vol. 3, n. ${ }^{\circ}$ 1, 2003, pp. 1-24.
} 
Sem entrar nos pressupostos fundamentais da integração regional ${ }^{42}$, é de constatar a ausência nítida desses pressupostos no actual processo de integração da SADC. Com efeito, apesar da palavra "integração" estar localizada no corpo do Tratado constitutivo da SADC - mais particularmente, no Preâmbulo, no n. ${ }^{\circ} 2$, do Artigo $21 .^{\circ} \mathrm{e}$ no n. ${ }^{\circ}$, do Artigo 22. ${ }^{\circ}$ - ou em alguns protocolos ${ }^{43}$ e com o objectivo de criar uma união quase total ${ }^{44}$, deve razoavelmente concluir-se que o processo de integração desta organização é, de jure e de facto, uma "Pseudo-Integração" 45 que peca, principalmente, por uma dupla ausência de técnicas integrativas (1) e de uma visão global da integração (2), o que faz com que a SADC seja apenas uma organização de cooperação (3). Facto sintomático, o termo "integração" não está contemplado, formalmente, em alguns protocolos da $\mathrm{SADC}^{46}$.

\section{A ausência de técnicas integrativas}

O que oferece a SADC em termos de instrumentos de integração jurídica? Será que a SADC promoveu técnicas de harmonização dos direitos nacionais dos Estados Membros? Será que a SADC elaborou um Direito Comum? Será que a SADC optou pela integração jurídica por via de convenções internacionais? O Tratado da SADC, não consagra nenhum instrumento que permite razoavelmente concluir pela existência de um real processo de uniformização das legislações dos Estados Membros. Neste sentido conclui claramente, o estudo promovido pelo SEPAC, em 1999: “ ... SADC has not yet

42 Vide, em particular, CISTAC, Gilles, "Como fazer da SADC uma organização regional verdadeiramente integrada?”, em, CISTAC, Gilles, Aspectos Jurídicos da Integração Regional, op. cit., p. 287 ss.

${ }^{43}$ Vide, por exemplo, o Preâmbulo do Protocolo de cooperação no domínio da Energia da SADC de 24 de Agosto de 1996, o Preâmbulo do Protocolo sobre o Sector Mineiro da SADC de 8 de Setembro de 1997 ou o Preâmbulo do Protocolo sobre as trocas comerciais na Região da SADC de 24 de Agosto de 1996.

${ }^{44}$ Mercado Comum, União Económica e Monetária e Moeda Única.

${ }^{45}$ ZACARIAS MACHAVA, Almeida, "SADC, uma "Pseudo-Integração" regional a caminho da União Aduaneira", Separata da Revista "Temas de Integração", 1. e 2. ${ }^{\circ}$ Semestres de 2010, n. 29 e 30, pp. 233-252.

${ }^{46}$ O termo "integração" nem aparece no texto do Protocolo sobre o Desenvolvimento do Turismo na Região da SADC de 14 de Setembro de 1998 e nem na definição dos "Terms and Concepts" da obra de GABRIËL H. OOSTHUIZEN (op. cit., p. 45ss.). 


\section{Doctrina y Jurisprudencia}

undertaken a programme of business law harmonization ..." ${ }^{47}$. Pelo contrário, o

objectivo é de "cooperar", isto é, coordenar a acção dos Estados Membros num domínio determinado. O instrumento privilegiado desta opção é o "Protocolo"48. Assim, esses acordos entre Estados Membros aparecem como instrumentos particularmente indicados e adaptados pela promoção de uma cooperação entre Estados ${ }^{49}$.

Todavia, esses instrumentos não são realmente concebidos para lutar contra a disparidade das quinze legislações nacionais que constituem um obstáculo pela realização de um espaço económico e social verdadeiramente integrado. Além disso, esta segmentação, de facto e de direito tem efeito perverso porque é fonte de concorrência entre os próprios Estados no seio da organização; alguns Estados tendo sistemas jurídicos mais atractivos do que outros. Será este modelo integrativo que os Estados Membros da SADC pretendem? De todo modo, "The whole endeavour of $S A D C$ is, therefore, focused on the implementation of sectoral protocols ${ }^{, 50}$.

Apesar da sua ratificação pela Cimeira de Chefes de Estados ${ }^{51}$, os protocolos são abertos à assinatura e ratificação dos Estados e não existe nenhum mecanismo que garante e assegure que todos os Estados Membros procedam, de modo uniforme ao cumprimento de todas essas formalidades. Na prática, pode-se medir os efeitos perversos e inadaptados desses instrumentos jurídicos para garantir um verdadeiro processo de integração. Os protocolos entram em vigor 30 dias após o depósito dos instrumentos de ratificação de dois terços dos Estados Membros ${ }^{52}$, o que deixa instalarse grandes incertezas sobre a implementação concreta dos protocolos, vista a lentidão

${ }^{47}$ SEPAC e BRISCOE, Andrew, Review of business laws in Southern Africa, Gaborone 1999, ed. Bonn: FES Library, 2000, p. 69 Disponível em: <http://library.fes.de/fulltext/bueros/botswana/00619toc.htm>. Acesso em: 29-09-2008.

${ }^{48}$ Artigo 22 do Tratado da SADC. Apesar da utilização da palavra "integração" neste artigo, o estudo do conteúdo dos diferentes protocolos demonstra claramente que o uso deste termo é nitidamente abusivo.

49 Até hoje, 25 protocolos foram aprovados nos sectores considerados como essenciais pelos Estados membros (Educação e Formação, Turismo, Sector Mineiro, Circulação de pessoas, Finança e Investimentos, Trocas comerciais, etc ...).

${ }^{50}$ SHAMS, Rasul, Regional Integration in Developing Countries: Some Lessons Based on Case Studies, Hamburg Institute of International Economics (HWWA), Discussion paper, 251, 2003, p. 23; como comenta o referido autor: "This is strongly reminiscent of the predecessor of the SADC i.e. SADCC (Southern African Development Coordination Conference)", Ibidem

${ }^{51}$ n. ${ }^{\circ} 3$ do Artigo 10 do Tratado da SADC.

${ }^{52}$ N. ${ }^{\circ} 4$ do Artigo 22 do Tratado da SADC. 
com a qual alguns Estados Membros ratificam ou ratificaram alguns protocolos ${ }^{53}$. Além disso, alguns protocolos previram um processo de denúncia ${ }^{54}$ ou retirada $^{55}$.

Mas, mesmo na hipótese em que um protocolo entra em vigor pelo cumprimento da condição acima referida, nada garante a uniformidade na adopção e aplicação de medidas internas visando o respeito das obrigações que ele impõe. Fenómenos de assimetrias na aplicação dessas disposições podem implicar incertezas e efeitos negativos nos operadores do comércio internacional. A admissão de um novo Estado Membro sob condição da sua aceitação de todos os instrumentos reconhecidos como importantes nos sectores essenciais da integração ${ }^{56}$ é apenas uma medida de circunstância que não garante a uniformidade na execução dos protocolos e que não constitui uma obrigação de comportamento pelo futuro. Além disso, os protocolos muito dificilmente poderão promover um interesse colectivo, pelo contrário, apenas serão promotores, no final, de uma soma de interesses estaduais.

Portanto, parece desenhar-se, na prática, uma SADC a geometria variável ${ }^{57}$ ou, por outras palavras, uma SADC constituída de Estados que ratificaram uma boa parte dos protocolos e que executaram as suas disposições e Estados Membros que ratificaram poucos protocolos e que têm, visivelmente, muitas dificuldades a implementá-los.

Mas, mesmo se o pressuposto de partida fosse uma escolha clara a favor dos protocolos como instrumentos de integração jurídica, pode-se verificar que, na prática, não foi esta via que foi explorada: não existe nenhum protocolo sobre a harmonização do Direito!

\footnotetext{
${ }^{53}$ NG'ONG'OLA, Clement, "Protocoles de la SADC: Réalisation à ce jour et le chemin qui nous attend", SADC - Barometer, Mars 2005, p. 8ss. Vide, também, sobre as dificuldades de implementação do Protocolo sobre as Trocas Comerciais, SULULO, Nicolau, "Liberalização do comércio e a integração económica regional. Desafios e Oportunidades", Maputo, Seminário sobre "Semana Aberta sobre o Sistema de Comércio Multilateral”, Junho de 2007 (np), p. 11.

${ }^{54}$ Vide, por exemplo, o Artigo 20 do Protocolo de Cooperação no Domínio da Energia; o Artigo 14.4 do Protocolo sobre Transportes, Comunicações e Meteorologia.

${ }^{55}$ Vide, por exemplo, o Artigo 15 do Protocolo sobre o Sector Mineiro.

${ }^{56}$ NG'ONG'OLA, Clement, "Protocoles de la SADC: Réalisation à ce jour et le chemin qui nous attend", op. cit., p. 10.

${ }^{57}$ NG'ONG'OLA, Clement, Ibidem; CLEARY, Séan, "Variable Geometry and Varying Speed: An Operational Paradigm for SADC", em, CLAPHAN C., MILLS G., MORNER A. e SIDIROPOULOS E. (Editors), Southern Africa: Comparative International Perspectives, Published by SAIIA, January 2001, pp. 87-104.
} 


\section{Doctrina y Jurisprudencia}

Pode-se concluir por uma ausência total de técnicas jurídicas capazes de favorecer o processo de integração da SADC. A razão fundamental é de que a escolha dos protocolos como instrumento de "Pseudo-Integração" permite evitar riscos de limitação da soberania dos Estados. É a soberania dos Estados que, de facto, paralisou o processo de integração. O actual funcionamento da SADC não violenta uma sociedade de justaposição de entidades soberanas.

\section{A ausência de uma visão global da integração}

A leitura do Plano Estratégico Indicativo de Desenvolvimento Regional, que estabelece os objectivos e as prioridades nos domínios de intervenção da SADC até 2019, permite concluir que a visão que foi consagrada é apenas uma visão "economicista" da integração e facto relevante, é apenas o termo "Economic Integration” que é definido no Glossário que acompanha o referido Plano quando se trata de definir o processo de integração como se existisse apenas uma única dimensão da integração. Por outras palavras, é uma visão unilateralista que foi consagrada pelos autores do Plano Estratégico negligenciando outros aspectos, não menos importantes, do processo de integração.

Nesta visão, as prioridades consagradas pelo Plano são essencialmente - senão exclusivamente económicas - (harmonizar as políticas macroeconómicas ${ }^{58}$, prosseguir a estabilidade e a convergência macroeconómica ${ }^{59}$, das políticas fiscais e monetárias ${ }^{60}$ ) e financeiras (liberdade de circulação dos capitais, liberalização do sector bancário e dos mercados financeiros ${ }^{61}$ ); como afirma o próprio RISDP: “The challenge for the region is to create an environment that is conductive to the attainment of high and sustained rates of equitable economic growth and poverty reduction by overcoming the constraints of under-development and dependence on primary sectors of production, improving macroeconomic conditions and maintaining a conductive climate for

\footnotetext{
${ }^{58}$ RISDP, op. cit., p. 26ss.

${ }^{59}$ Vide, em particular, o Memoranda of Understanding on Macroeconomic Convergence de 8 de Agosto de 2002.

${ }^{60}$ RISDP, op. cit., p. 26.

${ }^{61}$ Idem, p. 27.
}

Universidad de Almería - Edificio Departamental de Ciencias Jurídicas - (Edif. D) Planta. 2, Despacho: 2.210 Ctra. Sacramento s/n - La Cañada de San Urbano 04120 Almería 


\section{Doctrina y Jurisprudencia}

increasing savings and investment" ${ }^{\prime 62}$. Além disso, "A look at the list of objectives of the

SADC shows that not regional integration but economic and political development is the principle motivation behind the creation of the organization " 63 .

Visto noutra vertente, a estratégia estabelecida pelo RISDP não contempla nenhum objectivo de integração jurídica: a integração jurídica não está sequer mencionada nas "Priority Intervention Areas" do RISDP. A integração regional é apenas vista como "means to realise economic and political objectives" 64.

Esta abordagem, caracteriza uma nítida continuidade de trabalho entre a SADC e a Southern African Development Co-ordination Conference (SADCC). Com efeito, era a abordagem económica que caracterizava o desempenho da SADCC através da implementação de projectos coordenados. A SADC, foi, de uma certa forma, afectada por esta opção política. Isto explica, claramente, a importância dos projectos no Programa de Acção da SADC. Todavia, "The predominance of the project approach means that regional integration is understood mainly as an economic development process and less so as an institutional development process through different stages from FTA over customs union, common market and monetary union up to political union ${ }^{, 65}$.

A consequência lógica desta abordagem hegemónica da visão económica da integração, é a ausência total de visão jurídica do processo integrativo. Além disso, outro efeito bastante negativo desta aproximação redutora é de que "Pouca gente - de Joanesburgo a Blantyre - conhece a SADC e menos ainda a considera como solução dos seus problemas sociais e económicos. A SADC é simplesmente um nome

\footnotetext{
${ }^{62}$ RISDP, Executive Summary, Chapter Two. É claro que essas diferentes acções são estreitamente dependentes uma das outras; como realça o RISDP: "As SADC establishes a Customs Union, it will be necessary to take steps to deepen monetary cooperation in the region which lead to the establishment of a monetary union. This process is linked to achieving macroeconomic convergence, stable and harmonized exchange rates systems, liberalization of the capital and current accounts transactions and adoption of market oriented approach to the conduct of monetary policy", idem, p. 65.

${ }^{63}$ SHAMS, Rasul, Regional Integration in Developing Countries: Some Lessons Based on Case Studies, op. cit., pp. 22-23.

${ }^{64}$ Idem, p. 23.

${ }^{65}$ Ibidem
} 
desconhecido por muita gente na região"66. Ou seja, a SADC não é "popular" e isto

pode enfraquecer duravelmente o seu processo de consolidação.

Esta observação é reforçada pelo método utilizado que se resume ao emprego de apenas duas técnicas: "eliminar/remover"67 e "não fazer"68. De facto, não se constrói nada em comum ou melhor, o que se trata de produzir não é a integração stricto sensu mas apenas um "legal framework for co-operation among Member States" 69 com a aprovação de protocolos nuns domínios escolhidos de um comum acordo pelos Estados Membros. Resumidamente, coopera-se, mas não se integra. Assim, o processo de integração no Tratado da SADC não foi pensado na sua globalidade porque as visões jurídicas e políticas ${ }^{70}$ estão puramente ausentes. Se não se pode desprezar a importância do factor económico no processo de integração regional, não se pode negar, também,

\footnotetext{
${ }^{66}$ VAN SCHALKWYK, Gina, "Un partenariat improbable", SADC - Barometer, janvier 2004, p. 1. Vide, também, LOGAN C., "Caractère spécial de la SADC dans l'esprit du public", SADC - Barometer, Août 2004, pp. 13-15.

${ }^{67}$ RISDP, op. cit., p. 24. Na perspectiva de criação de um Mercado Comum onde circularão livremente os factores de produção (vide a definição do "Common market" em Glossary do RISDP), remove-se as "Barreiras sobre o Comércio intra-SADC" (Artigo 3 do Protocolo sobre as trocas comerciais), as "Taxas de importação" (Artigo 4 do Protocolo sobre as trocas comerciais), as "Taxas de exportação" (Artigo 5 do Protocolo sobre as trocas comerciais), as "Barreiras não tarifárias" (Artigo 6 do Protocolo sobre as trocas comerciais). É um dos objectivos afirmados pelo Tratado da SADC (alínea d), n. ${ }^{\circ} 2$ do Artigo 5). Todavia, na prática, um autor afirmou que a "... inability and unwillingness of countries to remove tariff and non-tariff barriers to trade due to fiscal restraints, local industry protection and the fear of uneven distribution of costs and benefits", MEYN, Mareike, "The Progress of Economic Regionalization in Southern Africa - Challenges for SADC and COMESA", Conference Paper Prepared for the Namibian Economic Policy Research Unit (NEPRU), "Monitoring Regional Integration in Southern Africa", Windhoek June 11-12, 2005. Disponível em: 〈http://www.edc2010.net/pubs/pdf/meyn.pdf $>$. Acesso em: 29-09-2008, p. 1. Vide, também, o Artigo 5 do Protocolo sobre o Desenvolvimento do Turismo na Região da SADC de 14 de Setembro de 1998.

${ }^{68}$ Abster-se de impor quaisquer novas barreiras não-tarifárias, abster-se de aplicar quaisquer novas restrições quantitativas (artigos 6 e 7 do Protocolo sobre as Trocas Comerciais), abster-se de tributar duas vezes (RISDP, op. cit., p. 27), abster-se de conceder subsídios que possam distorcer ou ameaçar distorcer o espírito de concorrência na Região (Artigo 19) ou no objectivo de atrair os investimentos: " ... offering low corporate and personal income tax rates; tax holidays and exemptions on profits, dividends, interest and royalties; exemptions from import duties and sales tax on inputs and capital equipment; tax rebates ans drawbacks ..." (RISDP, op. cit., p. 27).

${ }^{69}$ RISDP, op. cit., p. 3.

${ }^{70}$ Não se pode razoavelmente defender que existe verdadeiramente uma "Political Union" no sentido definido por MAREIKE MEYN ("The Progress of Economic Regionalization in Southern Africa Challenges for SADC and COMESA", op. cit., p. 2 nota de roda pé 1 in fine) que pressupõe que as "Decisions over domestic policies are no longer made by member states but by a supranational organisation" (Idem).
}

Universidad de Almería - Edificio Departamental de Ciencias Jurídicas - (Edif. D) Planta. 2, Despacho: 2.210 Ctra. Sacramento s/n - La Cañada de San Urbano 04120 Almería 
que a sua orientação depende da vontade política dos Estados Membros.

Consequentemente, não se pode ver o elemento económico como o elemento que seria, em última análise, determinante da política de integração. Por outras palavras, apesar do facto de as considerações económicas intervêm na determinação da política geral de integração regional, essas não possuem nenhuma exclusividade porque no processo de integração da SADC que se quer global, outros factores intervêm igualmente (cultural, social, ambiental, jurídico, etc.).

\section{A SADC: uma organização de cooperação e não de integração}

A SADC é uma vasta organização de coordenação ${ }^{71}$, de harmonização de políticas, de planos, de programas, de estratégias ${ }^{72}$ e de projectos $^{73}$. Esta natureza tem implicações nos seus métodos de trabalho e na sua estrutura jurídico-organizativa.

No que concerne aos métodos de trabalho, pode-se dizer que esses não são muito diferentes daqueles vigentes na época da vigência da SADCC. Coordenam-se as políticas nacionais ${ }^{74}$ com mais ou menos sucesso. O Protocolo de cooperação no domínio da Energia da SADC de 24 de Agosto de 1996 materializa claramente esta

\footnotetext{
${ }^{71}$ Do ponto de vista histórico, pode-se observar que a cooperação é uma experiência antiga em África Austral. É este modo de relacionamento entre Estados que foi já afirmado com força na Declaração de Lusaka intitulada Southern Africa: Toward Economic Liberation de 1 de Abril de 1980 em que os Chefes de Estados de África Austral estabeleceram o quadro político das suas relações na Southern African Development Co-ordination Conference (SADCC). A título exemplificativo, a Declaração de Lusaka dispõe que: "In the interest of the people of our countries, it is necessary to liberate our economies from their dependence on the Republic of South Africa to overcome the imposed economic fragmentation and to coordinate our efforts toward regional and national economic development" ou "The welfare of the peoples of Southern Africa and the development of its economies requires coordinated regional action". Sobre os aspectos históricos, vide, OOSTHUIZEN G.H., op. cit., p. 59ss.

${ }^{72}$ RASUL SHAMS equacionou muito bem o problema questionando: "SADC: Development co-operation or regional integration?”, Regional Integration in Developing Countries: Some Lessons Based on Case Studies, op. cit., p. 22ss.

${ }^{73}$ Como escreve RASUL SHAMS: "Integration policy is concentrated on the realization of common projects rather than on creating an economic community (...) The predominance of the project approach means that the regional integration is understood mainly as an economic development process and less so as an institutional development process through different stages from FTA over customs union, common market and monetary union up to political union", ibid., pp. 30-31.

${ }^{74}$ Alínea a) do n. ${ }^{\circ} 2$ do Artigo 5 do Tratado da SADC.
}

Universidad de Almería - Edificio Departamental de Ciencias Jurídicas - (Edif. D) Planta. 2, Despacho: 2.210 Ctra. Sacramento s/n - La Cañada de San Urbano 04120 Almería 


\section{Doctrina y Jurisprudencia}

opção $^{75}$. Harmonizam-se programas e estratégias. O Protocolo sobre o Sector Mineiro da SADC de 8 de Setembro de 1997 constitui um bom exemplo disto ${ }^{76}$ : troca-se informações $^{77}$; promovem-se políticas ${ }^{78}$ e a harmonização de medidas administrativas e legislativas em matéria penal e civil (este Protocolo nem trata sequer de Direito económico ou Comercial $)^{79}$ ou aduaneiras ${ }^{80}$, mas nenhum desses instrumentos contribuem para se integrar verdadeiramente.

Na prática, o objectivo predominante da SADC, é o de fomentar relações multilaterais de mera cooperação entre os Estados Membros, na esfera da actividade económica correspondente apenas a uma parte do objecto material da organização que é muito mais rico (manutenção da paz, segurança, democracia, cultura, etc...).

No que diz respeito à estrutura jurídico-organizativa da SADC, esta não reflecte nenhuma limitação à soberania dos Estados Membros. Os mecanismos organizativos apenas desenvolvem relações horizontais de simples coordenação das soberanias estaduais. Os Estados Membros ainda desempenham um papel primordial na vida da SADC. Por exemplo, não há nenhuma previsão da intervenção directa da SADC na ordem interna dos Estados Membros. Por isso, as suas decisões e deliberações têm como destinatários os próprios Estados Membros e nunca os seus sujeitos internos, particularmente o indivíduo. Ou seja, o Estado Membro interpõe-se entre a SADC e a sua ordem interna. As decisões ou deliberações dos órgãos da SADC não têm efeito directo sobre os nacionais dos Estados Membros nem sobre as respectivas

\footnotetext{
75 "Pretendendo promover o desenvolvimento harmonioso das nossas políticas nacionais no domínio de energia, bem como aspectos de interesse comum para o desenvolvimento equilibrado e equitativo da energia em toda região da SADC" (Preâmbulo). O sublinhado é nosso.

${ }^{76}$ Vide igualmente, n. ${ }^{\circ} 10$ do Artigo 2 do Protocolo de cooperação no âmbito da Energia na SADC de 24 de Agosto de 1996.

${ }^{77}$ Vide por exemplo, o Artigo 6 do Protocolo de cooperação no Domínio da Energia na SADC de 24 de Agosto de 1996; Artigo 3 do Protocolo sobre o Sector Mineiro na SADC de 8 de Setembro de 1997; n. 2 do Artigo 8 do Protocolo sobre o Desenvolvimento do Turismo na Região da SADC de 14 de Setembro de 1998.

${ }^{78}$ Vide, por exemplo, o n. ${ }^{\circ} 1$ do Artigo 7 do Protocolo sobre o Sector Mineiro na SADC de 8 de Setembro de 1997; Preâmbulo do Protocolo sobre o Desenvolvimento do Turismo na Região da SADC de 14 de Setembro de 1998.

${ }^{79}$ Alínea i) do Artigo 2 do Protocolo sobre Assuntos jurídicos de 7 de Agosto de 2000.

${ }^{80}$ RISDP, op. cit., p. 25.
} 
administrações. Com efeito, se os protocolos são aprovados pela Cimeira sob recomendação do Conselho ${ }^{81}$, estes são sujeitos à ratificação dos Estados Membros ${ }^{82} \mathrm{o}$ que significa que apesar desta decisão da Cimeira, o efeito directo é ainda inexistente nas ordens jurídicas internas dos Estados Membros. Em resumo, não há transferência de poderes soberanos dos Estados Membros para a SADC.

Assim, a SADC terá muitas dificuldades em se integrar porque esta organização não dispõe de instrumentos jurídicos para tal. Por outras palavras, a SADC não criou verdadeiros instrumentos jurídicos que permitissem a substituição das disparidades de legislações dos Estados Membros num regime jurídico harmonizado ou uniformizado. Como qualquer organização cujo objectivo é a cooperação internacional ${ }^{83}$, a SADC tem um carácter estritamente interestadual e as suas decisões são dirigidas aos Estados Membros. De facto, a SADC institui o que alguns autores chamaram de "regionalismo de cooperação" ${ }^{\prime 4}$, em que os Estados promoveram um conjunto de solidariedades económicas com vista a estimular as trocas comerciais. Todavia, este tipo de regionalismo permanece respeitoso às soberanias dos Estados Membros. A SADC não impõe nenhuma verdadeira limitação de soberania aos Estados Membros ao contrário do "regionalismo de integração" que tem outros objectivos ${ }^{85}$; como escreve JAN BOHANES: "Economic integration in SADC is still partially viewed through a national sovereignty lens and has not yet acquired the kind of "technical character" which would allow trade-related disputes to be brought to the fore and "fought out" without affecting the general political climate under pinning the integration efforts"

Esta situação, acima descrita, tem, sem dúvida, uma influência sobre o modo de regulação do investimento estrangeiro.

\footnotetext{
${ }^{81}$ N. ${ }^{\circ} 2$ do Artigo 22 do Tratado da SADC.

${ }^{82}$ N. ${ }^{\circ} 4$ do Artigo 22 do Tratado da SADC.

${ }^{83}$ DREYFUS, Simone, Droit des relations internationales. Éléments de Droit international public, 4. ${ }^{\mathrm{a}}$ ed., Paris, Éditions Cujas, 1992, p. 104; GONÇALVES PEREIRA, André e DE QUADROS, Fausto, Manual de Direito Internacional Público, 3. . . ed., Coimbra, Edições Almedina, 2000, p. 421ss.

${ }^{84}$ CARREAU, Dominique e JUILLARD, Patrick, Droit international économique, 3. a ed., Paris, Éditions Dalloz, 2007, n. ${ }^{\circ} 57$.

${ }^{85}$ Idem, n. ${ }^{\circ} 58$.

${ }^{86}$ BOHANES, Jan, "A Few Reflections on Annex VI to the SADC Trade Protocol”, tralac Working Paper, No3/2005, June 2005, p. 5.
} 


\section{b) A influência do sistema vigente sobre o modo de regulação do investimento estrangeiro pelo Direito comunitário}

A forma e a prática de que como se pensa o processo de integração regional na SADC têm incidências sobre o quadro jurídico regulador dos investimentos. Com efeito, se este quadro é dominado por traços relacionais cooperativos, os instrumentos jurídicos produzidos pela "Comunidade" serão, também, influenciados por esta abordagem. Vê-se já que o Protocolo e o Anexo 1, do ponto de vista terminológico e estrutural, utilizem substancialmente os elementos integrados nos acordos internacionais de promoção e protecção do investimento, isto é, instrumentos jurídicos dominados pelos princípios do Direito Internacional Público. Isto significa, claramente, que a dimensão integrativa não é a principal preocupação dos autores desses instrumentos. Facto digno de relevo é o relacionado com a obrigação de harmonizar as legislações nacionais sobre o investimento. Esta operação, pelo menos, integra-se num processo de integração regional.

"It is generally recognized" escreve ZHU WEIDONG, "that diversified legal systems will impede the international commercial activity and have negative effects on the commercial transactions between African merchants and foreign business partners, especially foreign investment in Africa and trade between Africa and others countries" ${ }^{\$ 7}$. É por esta razão que o Artigo 19 do Anexo 1 recomenda aos Estados Partes a harmonização de regimes de investimento "... de acordo com as melhores práticas no âmbito da estratégia geral para se atingir a integração regional". O processo de harmonização das legislações nacionais relativas ao investimento é um processo bastante complexo. Na sua essência, como qualquer processo de harmonização jurídica, a harmonização dos regimes jurídicos nacionais do investimento consiste em aproximar estas legislações suprimindo as suas divergências e as suas disparidades ${ }^{88}$. Nesta perspectiva, várias fases devem ser logicamente encaradas para tomar toda a medida da complexidade deste processo. Em primeiro lugar, deve-se interrogar-se sobre o objecto da harmonização: o que é necessário harmonizar em matéria de investimento?

\footnotetext{
${ }^{87}$ WEIDONG, Zhu, "China-African Trade \& Investment and the Exchange of Law", em, AA. VV., The Harmonization of Commercial Laws in Africa and its Advantages for Chinese Investments in Africa, Salvador Mancuso, org., Macao, Institute for Advanced Legal Studies, 2008, p. 107.

${ }^{88}$ De forma geral, vide, CISTAC, Gilles, "Contribuição para a elaboração de uma estratégia para a harmonização do Direito Económico e Comercial na SADC”, op. cit., p. 73ss.
} 
Em segundo lugar, deve reflectir-se sobre as técnicas de harmonização tomando em conta todas as especificidades do ambiente no qual essas técnicas serão desenvolvidas: como harmonizar? e por último, o processo de harmonização desenvolvera-se num espaço-tempo o que significa definir prazos para a realização do processo de harmonização. Contudo, este processo está, ainda, numa fase embrionário pelo facto de não existir uma real vontade, por parte de alguns Estados Membros. de o iniciar; como refere um estudo recente: "Member states will be reluctant to harmonise where this impacts their ability to compete and where it is not in the national interest to do so" ${ }^{89}$.

Esta ausência de vontade política dos Estados Membros é, principalmente, devida aos riscos que uma harmonização das legislações nacionais em matéria de investimento pode fazer correr às políticas nacionais fundamentadas nos benefícios fiscais atractivos capazes de seduzir os investidores estrangeiros. $\mathrm{O}$ facto de harmonizar essas legislações significaria, de facto, para alguns Estados Membros, baixar o nível de atractividade dos investimentos estrangeiros oferecendo menos benefícios. Este problema deve se situar numa conjectura mais abrangente: será que o processo de integração regional é compatível com normas não harmonizadas em determinados sectores chaves desta organização? De facto, a harmonização ou a uniformização dos direitos nacionais constitui um meio de combate contra quadros jurídicos laxistas. Com efeito, a instituição de normas jurídicas comuns permite lutar eficazmente contra os fenómenos de "dumping social" e de "dumping ecológico" "90. Pode-se dificilmente admitir que numa mesma organização regional as escolhas dos operadores económicos sejam ditadas pelas normas sociais menos avançadas no plano do progresso social ou os padrões de defesa do ambiente mais baixos quando o objectivo desta mesma organização é construir uma “Comunidade". Do mesmo modo, será que a ausência de harmonização jurídicas no sector do investimento não provoca uma distorção das normas que devem regular uma concorrência saudável em matéria de atracção do investimento estrangeiro?

\footnotetext{
${ }^{89}$ SADC, Protocol on Finance and Investment. Baseline Study: Regional Report, op. cit., p. 37.

${ }^{90}$ Sobre todos estes aspectos, cfr., LOUNGNARATH, Vilayson, "L'intégration juridique dans la zone ALÉNA: un chantier axé sur les processus", Revue du Barreau/Tome 61/Printemps 2001, p. 10ss.
} 


\section{ACOLHEDOR}

Apesar da consagração de um leque de competências exclusivas para o Estado Acolhedor em matéria de determinação do regime jurídico do investimento estrangeiro, o Protocolo e o seu Anexo 1 consagram, igualmente, algumas inflexões às referidas competências. Algumas constituem verdadeiros limites à competência exclusiva do Estado Acolhedor em matéria de determinação do regime jurídico do investimento (A), enquanto outras são meras recomendações ou orientações (B).

\section{A. Os limites à competência exclusiva do Estado Acolhedor em matéria de determinação do regime jurídico do investimento}

As competências exclusivas do Estado Acolhedor em matéria de determinação do regime jurídico do investimento sofrem alguns limites consagrados no Anexo 1 e que, consequentemente, constituem um verdadeiro estatuto do investimento estrangeiro que faz contrapeso ao "direito disciplinar" do Estado Acolhedor. Principalmente, esses limites articulam-se em torno do regime da admissão do investimento (a), da protecção do investimento (b) e da intervenção do sistema de convenções bilaterais sobre a promoção e protecção do investimento estrangeiro que pode moderar o princípio de exclusividade estadual (c).

\section{a) A consagração do princípio de previsibilidade da legislação aplicável em matéria}

\section{de investimento}

O n. ${ }^{\circ} 3$ do Artigo 2 do Anexo 1 estabelece um limite ao poder de livre decisão do Estado Acolhedor em matéria de admissão de investimentos. Com efeito, nos termos da referida disposição: "Para efeitos de criação de um clima de investimento previsível, os Estados Partes acordam em não emendar ou modificar, arbitrariamente, e sem justificação fundamentada, os termos, as condições e quaisquer benefícios especificados no documento de autorização, em detrimento dos investidores". Esta disposição expõe, ao mesmo tempo, a razão e as situações de facto que limitam o poder de livre decisão do Estado Acolhedor. 


\section{Doctrina y Jurisprudencia}

Em primeiro lugar, o fundamento do limite do poder de livre decisão do Estado

Parte reside na previsibilidade do direito que será aplicado ao investimento ("um clima de investimento previsível"). Por outras palavras, o investidor deve ter a possibilidade de prever, desde o princípio da operação de investimento, o conteúdo do direito do Estado Acolhedor que regerá o seu investimento com toda a transparência e certeza possível sobre tudo quando trata-se de um investimento de longo prazo. Para o investidor esta condição constitui um elemento fundamental de segurança jurídica. Com efeito, o investidor deve poder medir todos os riscos relacionados à operação de investimento num determinado Estado Parte e o estado do direito que regula o investimento constitui um elemento a tomar em consideração. No caso em que o investidor mediu o risco relacionado a um determinado estado de direito, num determinado momento, e que, posteriormente, o Estado Acolhedor modifica ou altera, sem justificação, este estado, esta nova situação pode prejudicar a previsibilidade do investidor na medida em que ele tinha projectado a sua operação de investimento tomando em conta um determinado estado de direito (por exemplo, uma determinada taxa de imposto sobre o rendimento ou o livre repatriamento de investimentos e retornos).

Em segundo lugar, em termos de objecto do limite do poder de livre decisão do Estado Acolhedor, é o próprio "documento de autorização", que constitui um acto administrativo constitutivo de direitos. Com efeito, deste documento resultará uma alteração na esfera jurídica do investidor, nomeadamente, pelos direitos que lhe foram concedidos através deste documento. Pois, este documento não pode ser revogado ou alterado de forma arbitrária. Este limite jurídico não deve estranhar. Se olha-se pelos países de regime administrativo, como Moçambique, por exemplo, pode-se verificar que o mesmo princípio foi consagrado no que concerne a revogação dos actos administrativos constitutivos de direitos. Assim, de acordo com o n. ${ }^{\circ} 2$ do Artigo 126 da Lei n. ${ }^{\circ}$ 14/2009, de 17 de Março ${ }^{91}$ : "Os actos manifestamente ilegais ou outros, ainda que constitutivos de direitos, podem ser rectificados, suspensos ou revogados nos termos do número anterior, desde que não tenham produzido efeitos" (o sublinhado é nosso). Do mesmo modo, nos termos da alínea b) do n. ${ }^{\circ} 1$ do Artigo 136 da Lei n. ${ }^{\circ}$

\footnotetext{
${ }^{91}$ Lei n. ${ }^{\circ}$ 14/2009: Aprova o Estatuto Geral dos Funcionários e Agentes do Estado, abreviadamente designado por EGFAE, B.R., 17 de Março de 2009, 3. ${ }^{\circ}$ Suplemento, I Série - N. ${ }^{\circ} 10$.
} 
14/2011, de10 Agosto $^{92}$, os actos administrativos válidos são livremente revogáveis, salvo nos seguintes casos: "b) quando forem constitutivos de direitos ou de interesses legalmente protegidos”. Isto significa claramente que o poder da Administração Pública é limitado desde que o acto constitutivo de direitos tenha produzido efeitos jurídicos e, consequentemente, a Administração Pública deve respeitar as situações jurídicas que ela tenha criado em proveito do investidor. Contudo, o n. ${ }^{\circ} 3$ do Artigo 2 do Anexo 1 não procedeu a uma estabilização do direito do Estado Acolhedor como se pode encontrar em alguns contratos internacionais ${ }^{93}$, por exemplo, as cláusulas de estabilização fiscal que se encontram em alguns contratos petrolíferos ${ }^{94}$ ou convenções bilaterais sobre a protecção e a promoção dos investimentos ${ }^{95}$. Com efeito, modificações não arbitrárias e fundamentadas podem ter efeitos válidos em relação às condições e benefícios especificados no documento de autorização. Encontra-se, também, no direito interno de alguns Estados Partes, em particular, Moçambique, a faculdade de revogar um acto administrativo constitutivo de direitos quando “... desfavoráveis aos interesses dos seus destinatários, bem como quando todos os interessados dêem a sua concordância à revogação do acto ...” (n. 2 do Artigo 136 da Lei n. ${ }^{\circ}$ 14/2011, de 10 de Agosto). Assim se pode verificar, no último exemplo, que a modificação de um acto constitutivo de direitos é condicionada à vontade ou interesse do seu destinatário.

\section{b) As normas de protecção do investimento como moderador da competência} exclusiva do Estado Acolhedor

\footnotetext{
${ }^{92}$ Lei n. ${ }^{\circ}$ 14/2011: Regula a formação da vontade da Administração Pública, estabelece as normas de defesa dos direitos e interesses dos particulares, e revoga a Reforma Administrativa Ultramarina (RAU) e o Decreto-Lei n. ${ }^{\circ} 23229$, de 15 de Novembro de 1933, B.R., 10 de Agosto de 2011, I Série - N. ${ }^{\circ} 32$.

93 Vide, o debate sobre as cláusulas de estabilização na sentença arbitral AMINOIL, BURDEAU, Geneviève, "Droit international et contrats d'États. La sentence AMINOIL C. KOWEÏT du 24 mars 1982”, AFDI 1982, Vol. 28, p. 467ss.

${ }^{94}$ Em alguns contratos petrolíferos encontram-se cláusulas de estabilização fiscal na qual o Estado compromete-se a não modificar ou alterar as normas de carácter fiscal aplicáveis no decurso da execução do contrato. Por outras palavras, o Estado renuncia, no futuro, a estender a aplicação de novas normas fiscais a um determinado contrato (vide, por exemplo, Victor Stéphane ESSAGA, Interview, Lettre de la semaine, le 11 août 2008.2 Disponível http://www.afritaxes.com/new/?bnid=56\&SessionID=I6ZD4ZML6EYPX6GKZTG5MKXTIT8TZO\&this $\underline{\mathrm{id}=95 \& \mathrm{ctry}=0 \& \text { theme }=0 \& \text { ekat }=0}>$. Acesso em: $31-10-2012)$.

${ }^{95}$ LAVIEC, Jean-Pierre, op. cit., pp. 54-55.
} 
Os aspectos essenciais da protecção dos investimentos são constituídos por um conjunto de disposições relacionadas com as medidas de expropriação e nacionalização ${ }^{96}$. Com efeito, sob o epígrafe "Protecção de Investimentos", o Artigo 5 do Anexo 1 do Protocolo estabelece que: “Os investimentos não serão nacionalizados ou expropriados no território de qualquer Estado Parte, a menos que tais medidas sejam tomadas para fins de utilidade pública, de acordo com o devido processo legal, com base não discriminatória e sujeitas a uma indemnização imediata, adequada e efectiva”. O referido artigo não proíbe, aos Estados Partes, de nacionalizar ou expropriar os investimentos estrangeiros ${ }^{97}$, apenas o referido artigo estabelece condições para fazê-lo. Três condições são expressamente estabelecidas para proceder as referidas operações: fins de utilidade pública (1), um devido processo legal (2) e o respeito pelo princípio de não discriminação (3). De facto, o Artigo 5 do Anexo 1 estabelece condições já consagradas no Direito Internacional ${ }^{98}$. O Artigo 5 do Anexo 1 como o Direito Internacional $^{99}$ consagra a existência de uma obrigação de indemnizar os investidores estrangeiros por medidas de nacionalização ou expropriação (4).

\section{A utilidade pública}

De acordo com o Artigo 5 do Anexo 1 do Protocolo: “Os investimentos não serão nacionalizados ou expropriados no território de qualquer Estado Parte, a menos

\footnotetext{
${ }^{96}$ Sobre a definição dessas noções, vide, BROWNLIE, Ian, Principles of Public International Law, 4. ${ }^{\text {a }}$ ed., Oxford, ELBS - Oxford University Press, 1990, p. 531; SCHONARD, Pascal, La protection internationale des investissements étrangers: Quel impact sur les politiques publiques des États d'accueil?, ENA, Promotion Romain Gary - 2003-2005 - Cycle International Long, Master en Administration Publique, Disponível em: 〈http://www.ena.fr/index.php?/fr/recherche/memoiresmasters/map/CIL-2005/schonard> Acesso em: 22-08-2012, p. 10; DAILLER, Patrick et ali. Droit international public, 8. ${ }^{\text {a }}$ ed., Paris, LGDJ - Lextenso éditions, 2009, p. 1220.

${ }_{97}$ É um direito reconhecido ao Estado pelo Direito Internacional, DAILLER, Patrick et ali. Droit international public, op. cit., p. 1220; LAVIEC, Jean-Pierre, ibid., p. 177. Vide, também, a sentença arbitral LIAMCO, RAMBAUD, Patrick, "Un arbitrage pétrolier: la sentence LIAMCO", AFDI 1980, Vol. 26, p. 281ss.; a sentença arbitral TEXACO/CALASIATIC, CANTEGREIL, Julien, "The Audacity of the Texaco/Calasiatic Award: René-Jean Dupuy and the Internationalization of Foreign Investment Law", EJIL 2011, Vol. 22, p. 448.

${ }_{98}^{98}$ Sobre os aspectos de Direito Internacional, vide, LAVIEC, Jean-Pierre, ibid., p. 172ss.

${ }^{99}$ Este princípio foi reconhecido desde muito tempo pelo Direito Internacional (LAVIEC, Jean-Pierre, Protection et promotion des investissements. Étude de droit international économique, op. cit., p. 189ss.; DAILLER, Patrick et ali. Droit international public, op. cit., p. 1223ss.), independentemente das normas estabelecidas nas legislações internas vide, por exemplo, Artigo 82 da Constituição (Moçambique); . $^{\circ} 2$ do Artigo 13 da Lei n. ${ }^{\circ}$ 3/93, de 24 de Junho. Ele foi reafirmado pela Resolução 1803 (XVII) da Assembleia Geral das Nações Unidas, de 14 de Dezembro de 1962 com o título "Soberania permanente sobres os Recursos Naturais" e consagrado pela jurisprudência arbitral internacional, vide, por exemplo, a sentença LIAMCO, RAMBAUD, Patrick, "Un arbitrage pétrolier: la sentence LIAMCO", op. cit., p. 286ss.
} 


\section{Doctrina y Jurisprudencia}

que tais medidas sejam tomadas para fins de utilidade pública ..." (o sublinhado é nosso). Assim, a expropriação ou a nacionalização deve ser motivada pela "utilidade pública". Esta norma é tradicionalmente reconhecida como uma regra do Direito Internacional $^{100}$ e consta da Resolução 1803 (XVII) da Assembleia Geral das Nações Unidas, de 14 de Dezembro de 1962. Paradoxalmente, se as legislações nacionais fazem referências, comummente, a esta norma ${ }^{101}$, o que suscitou, regra geral, numerosas decisões jurisdicionais nos respectivos ordenamentos jurídicos internos, no Direito Internacional os precedentes (arbitrais) e os pontos de referência são menos numerosos. Tradicionalmente, cabe ao Estado Acolhedor de determinar o conteúdo da "utilidade pública" ${ }^{102}$. Contudo, se a avaliação e controlo pelos árbitros internacionais se revela muito superficial ${ }^{103}$, algumas sentenças arbitrais demonstraram o desejo de verificar o cumprimento desta condição. Na sentença arbitral ANTOINE GOETZ et consorts c. République du Burundi, de 29 de Janeiro de $1999^{104}$, o Tribunal Arbitral decidiu verificar se as medidas privativas ou restritivas de propriedade ou tendo um efeito similar tomadas pelo Governo Burundês eram internacionalmente licitas; como referiu o Tribunal: “C'est seulement lorsque l'une de ces conditions ne se trouve pas satisfaite que l'État d'accueil peut être regardé comme ayant contrevenu à ses obligations internationales en vertu de la Convention ...” (§. 125). É nesta perspectiva que o Tribunal Arbitral verificou se as medidas tomadas contra a demandada eram ou não internacionalmente lícitas o que implicava controlar se essas medidas eram tomadas numa perspectiva de “... utilidade pública, segurança ou interesse nacional ...” (§. 126). O Tribunal devia estabelecer, previamente, a norma de referência para efectivar o seu controlo e designou o direito nacional (burundês). O Tribunal Arbitral tomando em conta o conteúdo do processo verificou que, efectivamente, as medidas foram tomadas no interesse da economia nacional do país. Mais importante é a fundamentação de princípio que o Tribunal consagrou: “En l'absence d'erreur de droit ou de fait, d'erreur manifeste d'appréciation ou de détournement de pouvoir, il n'appartient pas au

\footnotetext{
${ }^{100}$ LAVIEC, Jean-Pierre, ibid., p. 187; DAILLER, Patrick et ali. ibid., p. 1223.

${ }^{101}$ Por exemplo, n. ${ }^{\circ}$ do Artigo 13 da Lei n. ${ }^{\circ}$ 3/93, de 24 de Junho (Moçambique).

${ }^{102}$ LAVIEC, Jean-Pierre, op. cit., p. 187.

${ }^{103}$ DAILLER, Patrick et ali. op. cit., p. 1223.

${ }^{104}$ ICSID ARB/95/3 - publicada em, 15 ICSID Review - Foreign Investment Law Journal, 2000, pp. 457-527.
} 
Tribunal de substituer son propre jugement à l'appréciation faite discrétionnairement par le Gouvernement du Burundi des "impératifs d'utilité publique ...ou d'intérêt national" (§. 126). Assim, o Tribunal Arbitral estabeleceu um princípio e várias excepções. O princípio é o tradicionalmente consagrado no Direito Internacional, o da competência exclusiva do Estado para determinar o que é o "interesse público". Contudo, várias excepções a este princípio são, ao mesmo tempo, estabelecidas pelo Tribunal. É de reparar que essas excepções - erro de facto ou de direito, erro manifesto de apreciação e desvio de $\operatorname{poder}^{105}$-, são conhecidas do Direito Administrativo e constituem os principais vícios que podem eivar um acto administrativo ${ }^{106}$. O Tribunal Arbitral verificou, pois, a legalidade administrativo das medidas privativa ou restritiva de propriedade como o podia ter feito um tribunal administrativo local em relação a esses vícios ${ }^{107} 108$, sem poder, todavia, anular essas decisões mas apenas tirar todas as consequências dessas ilegalidades em relação a uma medida de expropriação, como referiu o Tribunal Arbitral na sentença ADF GROUP INC. v. United States of America, de 9 de Janeiro de $2003^{109}$ : “... the Tribunal has no authority to review the legal validity and standing of the U.S. measures here in question under the US internal administrative law. We do not sit as court with appellate jurisdiction with respect to the U.S. measures" (§. 190).

A condição de "utilidade pública" vem reforçar o princípio de não discriminação; como refere JEAN-PIERRE LAVIEC: "Exigindo que as medidas de expropriação sejam prima facie tomadas no interesse da comunidade nacional, ela contribui para proibir que essas últimas sejam motivadas pelo intuito de prejudicar, pelo arbitrário ou pela retorsão em relação a um investidor estrangeiro" ${ }^{\prime 110}$.

\footnotetext{
${ }^{105}$ Por exemplo, a expropriação realizada para satisfazer os interesses privados de um agente do Estado.

${ }^{106}$ Vide, por exemplo, VEDEL, Georges e DELVOLVÉ, Pierre, Droit administratif, Tomo 2, 12. a ed., Paris, Presses Universitaires de France, 1992, p. 298ss.

${ }^{107}$ Vide, sobre a Justiça Administrativa no Burundi, CISTAC, Gilles, Code de Justice administrative du Burundi - Commenté et annoté, Bujumbura, Éditiond La Licorne, 2008, 146 p.

${ }^{108}$ A tentativa de importar no Direito internacional de Investimentos princípios do Direito Administrativo é "a visible factor", SORNARAJAH, Muthucumaraswamy, The International Law on Foreign Investment, Cambridge, Cambridge University Press, 2. ${ }^{a}$ ed., 2004, Third printing 2007, p. 341.

${ }^{109}$ Sentença arbitral ADF GROUP INC. vs. United States of America, de 9 de Janeiro de 2003 (ICSID ARB(AF)/00/1 - publicada em, 18 ICSID Review - Foreign Investment Law Journal, 2003, pp 195-289).

${ }^{110}$ LAVIEC, Jean-Pierre, op. cit., p. 188.
} 
O Artigo 5 do Anexo 1 submete as operações de expropriação e nacionalização à condição de um "devido processo legal”. Esta condição aparece, formalmente, como uma tradução do conceito anglo-saxónico de due processo of law ${ }^{111}$. Esta disposição pode ter duas interpretações. Em primeiro lugar, pode significar que a expropriação ou nacionalização deve respeitar princípios de Direito Internacional unanimemente reconhecidos e, em particular, o esgotamento das vias de recursos nacionais antes do início de um processo de resolução de conflitos pela via da arbitragem internacional ${ }^{112} \mathrm{e}$ a proibição da denegação de justiça ${ }^{113}$. Em segundo lugar, pode significar que as condições de forma definidas no direito interno do Estado Acolhedor deverão ser respeitadas. A regularidade da forma do processo de uma medida de expropriação ou nacionalização no direito interno não é uma condição determinante no plano do Direito Internacional $^{114}$. Contudo, na sentença arbitral Middle East Shipping and Handling Co. v. Egypt, o Tribunal Arbitral aceitou verificar a "due process of law" do cumprimento dos requisitos do procedimento da penhora e venda de um bem do investidor (barco) e constatou que: "Therefore, a matter as important as the seizure and auctioning of the ship of the Claimant should have been notified by direct communication for which the law $N^{\circ} 308$ provided under the $1^{\text {st }}$ paragraph of Art. 7, irrespective of whether there was a legal duty or practice to do so by registered mail with return receipt requested as argued by Claimant (CV 4). The Tribunal finds that procedure in fact applied here does not fulfill the requirements of Art. 2.2. and 4 of the BIT" ${ }^{\prime 115} \mathrm{e}$ ainda, "The Tribunal has found above the auction procedure applied here to have been "under process of law"

\footnotetext{
${ }^{111}$ A versão em língua inglesa deste artigo é a seguinte: "Investments shall not be nationalised or expropriated in the territory of any State Party except for a public purpose, under due process of law ... “ (o sublinhado é nosso).

${ }^{112}$ N. ${ }^{\circ} 1$ do Artigo 28 do Anexo 1 do Protocolo.

${ }^{113}$ SORNARAJAH, Muthucumaraswamy, The International Law on Foreign Investment, op. cit., p. 340.

${ }^{114}$ LAVIEC, Jean-Pierre, op. cit., p. 189.

${ }^{115}$ Sentença arbitral Middle East Shipping and Handling Co. S.A. vs. Arab Republic of Egypt, de 12 de Abril, de 2002, op. cit., §. 143.
} 


\section{Doctrina y Jurisprudencia}

(Art. 4. A) of the BIT) and specifically the notification procedure to have not been sufficient" ${ }^{\prime 16}$.

\section{O princípio de não discriminação}

Uma expropriação ou uma nacionalização não deve ser discriminatória. De acordo com o Artigo 5 do Anexo 1: “Os investimentos não serão nacionalizados ou expropriados no território de qualquer Estado Parte, a menos que tais medidas sejam tomadas para fins de utilidade pública, de acordo com o devido processo legal, com base não discriminatória ..." (o sublinhado é nosso). O princípio de não discriminação em relação à expropriação de bens estrangeiros é firmemente consagrado em Direito Internacional $^{117}$. Todavia, diferenças de tratamento entre os investimentos nacionais e estrangeiros são admitidas ${ }^{118}$. A questão central permanece de saber se um tratamento diferenciado é lícito ou, pelo contrário, constitui uma discriminação ilícita ${ }^{119}$. No que concerne o conteúdo do princípio, o critério básico da existência de um facto discriminatório reside na intenção de prejudicar que acarretam efeitos prejudiciais. Assim, a discriminação fundamenta-se numa intenção fraudulenta, e na ausência de legitimidade da medida tomada ${ }^{120}$. No caso de uma expropriação individual, o carácter discriminatório pode apreciar-se em relação as suas motivações, e ao tratamento particularmente injusto que seria reservado a um investidor estrangeiro. Se a expropriação se situa num programa colectivo de expropriações (por exemplo, por razões da edificação de uma barragem ou de um aeroporto internacional), existe a possibilidade de comparar a situação dos investidores estrangeiros a dos investidores

\footnotetext{
${ }^{116}$ Sentença arbitral Middle East Shipping and Handling Co. S.A. vs. Arab Republic of Egypt, de 12 de Abril, de 2002, op. cit., §. 147.

${ }^{117}$ CHARPENTIER, Jean, "De la non discrimination dans les investissements", AFDI 1963, Vol. 9, p. 41; LAVIEC, Jean-Pierre, ibid., p. 183; RAMBAUD, Patrick, “Arbitrage, concession et nationalisation: quelques observations sur la sentence B.P.”, AFDI 1981, Vol. 27, p. 225.

${ }^{118}$ Por exemplo, o Estado pode proibir a exploração de determinadas recursos naturais aos investidores estrangeiros ou atribuir um direito de preferência de exploração aos investidores nacionais. Nessas situações, "A discriminação é pois consagrada pela lei”, CHARPENTIER, Jean, ibid., p. 43. Pelo contrário, o Estado pode, também, conceder vantagens aos investidores estrangeiros que não concede aos investidores nacionais, vide, CHARPENTIER, Jean, ibid., p. 51ss.

${ }^{119}$ LAVIEC, Jean-Pierre, ibid., p. 91.

${ }^{120}$ CHARPENTIER, Jean, op.cit., p. 49ss.
} 
nacionais colocados na mesma situação. A protecção acordada pelo Estado Acolhedor não pode ser menos favorável para os investidores estrangeiros do que a concedida aos investidores nacionais. No caso de uma nacionalização, decidida pelo Poder legislativo, uma situação discriminatória poderia surgir se apenas os bens dos investidores estrangeiros são sujeitos a medidas de nacionalização ${ }^{121}$.

Contudo, será que a base da discriminação apenas pode ser a nacionalidade como afirma alguns autores ${ }^{122}$ ? No processo MIKE CAMPBELL vs. Republico of Zimbabwe $^{123}$, um dos elementos centrais era a discriminação fundada, não na nacionalidade, mas na "raça" ("racial discrimination" ${ }^{124}$ ). Os demandantes defendiam que a reforma agrária zimbabueana era baseada na discriminação racial porque esta reforma visava, exclusivamente, os fazendeiros brancos zimbabueanos: “There is a

\footnotetext{
${ }^{121}$ Além disso, a nacionalização de bens de investidores estrangeiros é bastante complexa porque integra várias situações diferentes, em particular, o caso de nacionalização de uma empresa estrangeira única (por exemplo, situação de monopólio) e o da nacionalização praticada como medida sancionatória. $\mathrm{Na}$ primeira hipótese, o carácter discriminatório pode resultar da análise das motivações do Estado e dos efeitos projectados (LAVIEC, Jean-Pierre, op. cit., p. 185; CHARPENTIER, Jean, ibid., p. 50ss.) e, consequentemente, uma nacionalização isolada pode inscrever-se, na realidade, numa política coerente de nacionalização que se efectiva gradualmente (vide, por exemplo, a sentença arbitral AMINOIL, BURDEAU, Geneviève, "Droit international et contrats d'États. La sentence AMINOIL C. KOWEÏT du 24 mars 1982”, op. cit., p. 467). Na segunda hipótese, a nacionalização tem o carácter de uma sanção. Foi o caso, em particular, na sentença B.P. na qual o Governo Líbio confessou, expressamente, que a medida visava, na realidade, o Governo britânico porque deixou o Irão ocupar três ilhas no Golfo Pérsico, RAMBAUD, Patrick, "Arbitrage, concession et nationalisation: quelques observations sur la sentence B.P.”, op. cit., p. 223; LAVIEC, Jean-Pierre, ibid., pp. 185-186. Consequentemente, o árbitro único declarou a nacionalização ilícita.

${ }^{122}$ Vide, por exemplo, LAVIEC, Jean-Pierre, ibid., p. 185.

${ }^{123}$ Vide, Tribunal da SADC, Case n. ${ }^{\circ}$ 2/2007, Mike Campbell (Pvt) e outros Vs The Republic of Zimbabwe - 28 de Novembro de 2008 (Disponível em: <http://www.sadctribunal.org/docs/case022007.pdf>. Acesso em: 19-10-2012), vide, ZIEGLER, Andreas R., "Regional economic integration agreements and investor protection in Africa - the case of SADC. Why institutional overlap may be necessary in certain cases", Swiss National Centre of Competence in Research, Working Paper $N^{\circ}$ 2011/59/May 2011, 20 p. Vide, também, Tribunal da SADC, Case n. ${ }^{\circ}$ SADC(T): 04/08, Andrew Paul Rosslyn Stidolph Vs The Republic of Zimbabwe - 28 de Março de 2008; Tribunal da SADC, Case n. ${ }^{\circ}$ SADC(T): 2/07, Mike Campbell (Pvt) Limites and William Michael Campbell Vs The Republic of Zimbabwe, 28 de Novembro de 2008. Vide, RUPPEL, C. Oliver e BANGAMWABO, X. François, "The SADC Tribunal: a legal analysis of its mandate and role in regional integration", Monitoring Regional Integration in Southern Africa, Vol. 8 (2008), p. 183ss.; N NDLOVU, Precious, "Campbell v Republic of Zimbabwe: A moment of truth for the SADC Tribunal", SADC Law Journal, Vo. 1, 2011, pp. 63-79. É a Reforma Agrária implementada no Zimbabué que deu origem a esses processos; sobre esta reforma, vide, DUBE, Memory e MIDGLEY, Rob, "Land reform in Zimbabwe: context, process, legal and constitutional issues and implications for the SADC region", Monitoring Regional Integration in Southern Africa, Vol. 8 (2008), pp. 303-341.

${ }^{124}$ Parte VI da sentença.
} 


\section{Doctrina y Jurisprudencia}

clear legislative intent directed only at white farmers ${ }^{125}$. Consequentemente, pelos autores da acção, as medidas de expropriação violavam, entre outros, o n. ${ }^{\circ} 2$ do Artigo 6 do Tratado da SADC que dispõe: "A SADC e os Estados Membros não discriminarão contra nenhuma pessoa com base no sexo, religião, pontos de vista políticos, raça, origem étnica, cultura, doença, incapacidade ou em qualquer outra razão que possa ser determinada pela Cimeira" (o sublinhado é nosso).

Assim, o Tribunal da SADC devia determinar se as medidas de expropriação violavam ou não a obrigação de não discriminação consagrada pelo Tratado da SADC. Antes de analisar o Direito Comunitário, o Tribunal fez lembrar que o Direito Internacional proíbe expressamente a discriminação ${ }^{126}$. Após ter citado o n. ${ }^{\circ} 2$ do Artigo 6 do Tratado, o Tribunal estabelece a premissa do seu raciocínio: "The question then is, what is racial discrimination?".

O Tribunal reconheceu que o Tratado da SADC não define o que é uma "racial discrimination". Perante esta situação, o Tribunal vai socorrer-se das definições e comentários, já existentes, oriundos de órgãos especializados na matéria e, mais particularmente, do Comité dos Direitos Humanos e do Comité sobre os Direitos Económico, Social e Cultural. No que concerne o primeiro, o Tribunal nota que o referido Comité, no seu Comentário N. ${ }^{\circ} 18$ sobre a não discriminação, no parágrafo 7 define a discriminação como: "any distinction, exclusion, restriction or preference which is based on any ground such as race, colour, property, birth or other status, and which has the purpose or effect nullifying or impairing the recognition, enjoyment or exercise by all persons, on an equal footing, of all rights and freedoms". No que concerne o uso dos comentários do Comité sobre os Direito Económico, Social e Cultural, o Tribunal implementou um raciocínio analógico transpondo o raciocínio do referido Comité, em matéria de igualdade de direitos entre homem e mulher, para o campo da discriminação racial; como referiu o Tribunal: "It is to be noted that what the Committee is stating about direct and indirect discrimination in the context of sex applies equally in the case of any other prohibited ground under the Covenent such as

\footnotetext{
${ }^{125}$ Nesta perspectiva, o critério da nacionalidade aparece como secundário. Os fazendeiros podiam ser oriundos, por exemplo, de um país europeu do momento que esses eram "brancos" podiam ser abrangidos pela expropriação.

${ }^{126}$ O Tribunal analisou vários instrumentos jurídicos para chegar a esta conclusão: Carta das Nações Unidas, a Declaração Universal dos Direitos Humanos, os Pactos das Nações Unidas sobre os direitos civis e políticos e sobre os direitos económicos, sociais e culturais, a Carta Africana dos Direitos Humanos e dos Povos.
} 
race”. Nesta perspectiva, o Tribunal notou que: "The Committe went on the state at paragraphs 12 and 13 respectively that: "Direct discrimination occurs when a difference in treatment relies directly and explicitly on distinctions based exclusively on sex and characteristics of men or women, which cannot be justified objectively”. "Indirect discrimination occurs when a law, policy or programme does not appear to be discriminatory but has a discriminatory effect when implemented" ".

É na operação de subsunção dos factos na norma de referência estabelecida pelo Tribunal que as questões podem se levantar e que, de facto se levantaram ${ }^{127}$. Na realidade, de acordo com o princípio geral de boa fé, que constitui um princípio geral de direito $^{128}$, deve-se presumir que uma medida de expropriação é válida, mesmo se abrange apenas uma determinada categoria de pessoas ${ }^{129}$; é, pois, ao demandante de comprovar que as medidas foram efectivamente discriminatórias. Além disso, a intenção de prejudicar este grupo de pessoas é necessária e suficiente para viciar a operação de expropriação. Nesta aproximação, o Tribunal afirma que: "Since the effects of the implementation of Amendment 17 will be felt by the Zimbabwean white farmers only, we consider it, although Amendment 17 does not explicitly refer to white farmers, as we have indicated above, its implementation affects white farmers only and consequently constitutes indirect discrimination or de facto or substantive inequality" e o Tribunal de deduzir: "In examining the effects of Amendment 17 on the applicants, it is clear to us that those effects have had an unjustifiable and disproportionate impact upon a group of individuals distinguished by race such as the Applicants. We consider that the differentiation of treatment meted out to the Applicants also constitutes discrimination as the criteria for such differentiation are not reasonable and objective but arbitrary and are based primarily on considerations of race (...) We, therefore, hold that, implementing Amendment 17, the Respondent has discriminated against the Applicants on the basis of race and thereby violated its obligation under Article 6(2) of the Treaty”.

Como foi estabelecido anteriormente, a boa fé do Governo Zimbabueano na concepção e implementação da reforma agrária deve ser presumida, o que significa que

\footnotetext{
${ }^{127}$ Vide, Dissenting opinion do Juiz ONKEMETSE B. TSHOSA.

${ }^{128}$ DREYFUS, Simone, Droit des relations internationales. Éléments de Droit international public, op. cit., pp. 150-151.
}

${ }^{129}$ CHARPENTIER, Jean, "De la non discrimination dans les investissements", op. cit., p. 51. 
o Tribunal deve, pois, demonstrar o intuito deste Governo de prejudicar os fazendeiros brancos expropriados. Em primeiro lugar, como referiu o Tribunal, formalmente, não havia uma explícita menção da "raça", etnicidade ou pessoas de determinada origem no Amendment 17 que fundamenta as expropriações e o Tribunal de reconhecer: "The question is whether, in the absence of the explicit mention of the world "race" in Amendment 17, that would be the end of the matter". O Tribunal podia ter ido mais longe e verificar se existia, por exemplo, discursos ou tomadas de posição objectiva e/ou oficial do Governo Zimbabueano dando a fundamentar a existência de um processo discriminatório de expropriação baseado na "raça", mas isto não foi realizado pelo Tribunal. Em segundo lugar, contrariamente à afirmação do Tribunal, o processo de expropriação abrangia, também, como foi mencionado na opinião vencida, "non-white Zimbabweans". De facto, "But even if numerically these other group of Zimbabweans is less compared to the white Zimbabweans farmers, the fact of the matter is that there are other Zimbabweans who are not white whose lands are affected by the Amendment"130 (o sublinhado é nosso). O Tribunal não explorou esta situação de facto e raciocinou sempre na hipótese da exclusiva expropriação de fazendeiros brancos e, consequentemente, construiu o seu raciocínio sobre este pressuposto duvidoso ${ }^{131}$. Em terceiro lugar, o intuito de prejudicar os expropriados não foi demonstrado pelo Tribunal. Partindo da análise dos efeitos, o Tribunal proibiu-se de investigar as verdadeiras causas do processo de expropriação, isto é, se houve ou não intuito, por parte do Governo do Zimbabué, de prejudicar os fazendeiros em razão da sua "raça". Com efeito, o Tribunal devia ter demonstrado que a expropriação dos fazendeiros brancos se justificava para atingir objectivos que permitem considerar que foi em razão do carácter racial que os prejuízos que sofreram os fazendeiros foram causados. Não é porque um determinado grupo de pessoas é exclusivamente abrangido por um processo de expropriação que forçosamente a sua razão de ser é de prejudicar o referido grupo ou

\footnotetext{
${ }^{130}$ Dissenting opinion. Como referiu o Juiz ONKEMETSE B. TSHOSA na sua opinião: “... Amendment 17 targets agricultural land and they are affected not because they are of white origin but because they are the ones own the land in question. Thus, the target of Amendment 17 is agricultural and land and not people of a particular racial group. This means that in implementing the Amendment it was always going to affect those in possession of the land be they of white, black or other racial background".

131 Por exemplo, "Since the effects of the implementation of Amendment 17 will be felt by the Zimbabwean white farmers only, we consider it, although Amendment 17 does not explicitly refer to white farmers, as we have indicated above, its implementation affects white farmers only and consequently constitutes indirect discrimination or de facto or substantive inequality" (o sublinhado é nosso).
} 


\section{Doctrina y Jurisprudencia}

actuar malevolamente. Curiosamente, o Tribunal voltou na mateira dos fundamentos da reforma agrária no fim da sua demonstração sentenciando que se "the lands expropriated were indeed distributed to poor, landless and other disadvantaged and marginalized individuals or groups, rendering the purpose of the programme legitimate...", substituindo, assim, a sua apreciação do interesse geral o do Governo do Zimbabué. Fundamentando assim, a decisão, será que o Tribunal não ultrapassou os seus poderes? O Governo do Zimbabué podia ter escolhido uma outra via - por exemplo, a gestão directa pela Administração Pública dos bens expropriados - e, neste caso, quid da fundamentação do Tribunal? O Tribunal explorou apenas uma dimensão do problema concluindo a ilicitude das medidas de expropriação porque prejudicaram um grupo de pessoas determinadas (sem ver que o grupo não era, finalmente, homogéneo) baseando assim, a sua decisão exclusivamente sobre os efeitos produzidos sem apreciar a sua razão de ser.

\section{A indemnização}

O Artigo 5 do Anexo 1 utiliza os termos "imediata" (4.2), "adequada" (4.1) e "efectiva" (4.3) para caracterizar a indemnização devida ${ }^{132}$. Assim, o Artigo 5 estabelece obrigações de indemnização - "imediata", "adequada" e "efectiva" - como condição de uma expropriação ou indemnização lícita. Em tudo caso, a determinação do montante de uma indemnização permanece uma questão de uma grande complexidade técnica devido a diversidade de situações possíveis na prática. Com efeito, o modo de avaliação da indemnização não é idêntico quando se trata da expropriação de direitos de propriedade sobre bens ou da expropriação de direitos decorrendo de um contrato, por exemplo, de um contrato de concessão sobre a exploração de recursos naturais ${ }^{133}$.

\subsection{O montante da indemnização: uma indemnização adequada}

${ }_{132}$ É a fórmula que se encontra na prática anglo-saxónica: “prompt, adequate and effective”. Vide,
SORNARAJAH, Muthucumaraswamy, The International Law on Foreign Investment, op. cit., p. 437ss.;
BROWNLIE, Ian, Principles of Public International Law, op. cit., p. 532ss. Esta fórmula é, também,
consagrada em numerosas convenções bilaterais sobre a promoção e protecção recíproca de
investimentos, vide, por exemplo, o n. ${ }^{\circ} 1$ do Artigo 3 do Tratado entre a República de Moçambique e os
Estados Unidos de América sobre a Promoção e Protecção Recíproca de Investimentos.

${ }^{133}$ LAVIEC, Jean-Pierre, op. cit., p. 198. 
"Uma indemnização adequada”, referem DOMINIQUE CARREAU e

PATRICK JUILLARD, “é pois uma indemnização que compreende uma reparação adaptado à medida particular de expropriação ou de nacionalização" ${ }^{134}$. É claro que esta adequação implica uma determinada margem de apreciação. Contudo, a tendência actual vai no sentido de uma tomada em conta do valor real dos bens expropriados ou nacionalizados ${ }^{135}$. Nesta perspectiva, deve-se tomar em conta dois aspectos no que concerne os métodos de avaliação da indemnização. Por um lado, é preciso tomar em conta a natureza dos bens expropriados ou nacionalizados (4.1.1.) e, por outro lado, a estrutura do mercado no país expropriando ou nacionalizando (4.1.2.).

\subsubsection{A natureza dos bens expropriados ou nacionalizados}

A natureza dos bens expropriados ou nacionalizados têm uma incidência sobre a escolha dos métodos de avaliação da indemnização. Bens considerados isoladamente não se avaliam da mesma forma do que uma universalidade de bens como é uma empresa em estado de funcionamento. É mesmo no caso de bens considerados isoladamente, estes não se avaliam da mesma forma, também, segundo se trata de títulos representativos do capital social de uma empresa ${ }^{136}$, ou se se trata dos elementos do activo ou passivo desta empresa ${ }^{137}$. Como reconhecem DOMINIQUE CARREAU e

\footnotetext{
${ }^{134}$ CARREAU, Dominique e JUILLARD, Patrick, Droit international économique, op. cit., p. 539. É esta abordagem - "appropriate compensation" - que foi escolhida pelo Tribunal Arbitral na sentença arbitral AMINOIL, HUNTER, Martin, e SINCLAIR, Anthony C., "Aminoil Revisited. Reflections on a Story of Changing Circumstances", op. cit., p. 362ss. Na sentença arbitral LG\&E Energy Corp. e outros vs República Argentina, de 25 de Julho de 2007 (ICSID ARB/02/1 - Disponível em: $<$ https://icsid.worldbank.org/ICSID/FrontServlet?requestType=CasesRH\&actionVal=showDoc\&docId= DC786_Sp\&caseId=C208> Acesso em: 29-09-2012), o Tribunal Arbitral decidiu que: "El silencio de un tratado en lo que concierne a este tema (indemnización) se interpreta como un indicio de la intención de las partes de "dejar en manos de los tribunales la elección de una medida de laindemnización adecuada para las circunstancias específicas del caso, teniendo en cuenta los principios del derecho internacional y lo estipulado por el TLCAN” (\$. 40).

${ }^{134}$ LAVIEC, Jean-Pierre, op. cit., p. 193ss.

${ }^{135}$ Id., ibid. É esta noção do "valor real” que encontra-se, a maior parte do tempo, na prática convencional e jurisdicional.

${ }^{136}$ É mesmo nesta situação, será necessário distinguir entre os que são estimados ou não em bolsa de valores. Na segunda hipótese, é comummente admitido que o valor em bolsa de valores do capital dá uma imagem bastante fiel do valor da empresa, na condição de excluir as flutuações do mercado consecutivas à decisão de expropriação, e mesmo quanto ao seu anúncio oficioso, vide, LAVIEC, Jean-Pierre, op. cit., p. 199.

${ }^{137}$ CARREAU, Dominique e JUILLARD, Patrick, op. cit., p. 541.
} 
PATRICK JUILLARD, “... os métodos podem e devem variar a fim de reflectir a

realidade económica” ${ }^{138}$. Em tudo caso, a dificuldade maior para delimitar o conceito

de indemnização adequada reside na avaliação do damnum emergens e da inclusão ou não do lucrum cessans. A distinção entre expropriação ou nacionalização lícita ou ilícita pode interferir no cálculo do quantum ${ }^{139}$. Com efeito, a indemnização, em caso de expropriação ou nacionalização ilícita, integra o damnum emergens e o lucrum cessans $^{140}$ mas será que uma expropriação ou nacionalização lícita inclui o mesmo quantum $^{141}$ ? Em tudo caso, como refere IGNAZ SEIDL-HOHENVELDERN, “... il faut admettre que l'on n'a pas réussi à dégager des règles sûres et uniformément acceptées de l'examen des récentes sentences traitant ces matières" ${ }^{142}$.

\title{
4.1.2. A estrutura do mercado no país expropriando ou nacionalizando
}

\begin{abstract}
${ }^{138}$ Id., ibid. Os referidos autores reconhecem, também, que existe uma “... relutância cada vez mais grande em utilizar apenas os valores contabilísticos, na medida em que estes, por várias razões, não traduzem exactamente a realidade económica e, mais particularmente, a situação da empresa expropriada ou nacionalizada quando encontra-se em estado de funcionamento", Idem. Na hipótese de uma avaliação de uma empresa, várias técnicas são frequentemente utilizadas: o valor contabilístico (book value), a capitalização dos lucros, o custo de substituição, o valor de mercado por analogia, o valor de capitalização em bolsa de valores e o valor inicial do investimento actualizado. Essas diferentes técnicas contabilísticas são utilizadas em função da situação concreta de uma empresa. Todas servem para avaliar o que constitui o valor comercial ou real de uma empresa. Contudo, o valor contabilístico dos haveres se avalia o damnum emergen, exclui o lucrum cessans. Os elementos incorporais do valor contabilístico, tais como a clientela ou o goodwill, podem ter tomado em consideração no caso em que são certos, quantificáveis e não especulativos (LAVIEC, Jean-Pierre, op. cit., p. 199). Sobre as técnicas de avaliação, vide a bibliografia citada por LAVIEC, Jean-Pierre, ibid., p. 198 nota de roda pé 207; SEIDLHOHENVELDERN, Ignaz, "L'évaluation des dommages dans les arbitrages transnationaux", AFDI 1987, Vol. 33, pp. 7-31.

${ }^{139}$ Vide, por exemplo, a sentença arbitral AMINOIL, HUNTER, Martin, e SINCLAIR, Anthony C., "Aminoil Revisited. Reflections on a Story of Changing Circumstances", op. cit., p. 361ss.

${ }^{140}$ LAVIEC, Jean-Pierre, op. cit., p. 193ss.

${ }^{141}$ Vide, o conhecido e sempre citado Acórdão da CPJI no caso Usine de Chorzow, CPJI, Série A, n. ${ }^{\circ} 17$, 1928 , p. 47. Na sentença LIAMCO, não houve dificuldade na indemnização damnum emergen - bens corporais nacionalizados (instalações, edifícios, equipamentos) -, o árbitro decidiu satisfazer o pedido do demandante neste sentido. No que concerne a indemnização do lucrum cessans, o árbitro não respondeu claramente a esta questão estatuindo em equidade e satisfazendo, parcialmente, alguns pedidos da demandante, RAMBAUD, Patrick, "Un arbitrage pétrolier: la sentence LIAMCO", op. cit., pp. 291-292. Na sentença arbitral AMINOIL, o Tribunal Arbitral não aceitou satisfazer à integralidade do pedido da demandante no que concerne o lucrum cessans mas “... it did include an allowance for legitimate expectation of the investor to a "reasonable rate of return" ...", HUNTER, Martin, e SINCLAIR, Anthony C., "Aminoil Revisited. Reflections on a Story of Changing Circumstances", op. cit., p. 365. Como refere DOMINIQUE CARREAU e PATRICK JUILLARD: "Et l'on constate une nette tendance, dans la pratique récente, à indemniser le lucrum cessans, même lorsque la mesure d'expropriation ou de nationalisation n'est pas regardée comme contraire aux principes du droit international. Certes, on n'ira pas jusqu'à la restitutio in integrum: mais une juste appréciation des intérêts en puissance amène à l'attribution d'une fraction équitable du lucrum cessans à l'investisseur exproprié ou nationalisé", op. cit., p. 543; SEIDL-HOHENVELDERN, Ignaz, "L'évaluation des dommages dans les arbitrages transnationaux", op. cit., p. 17; LAVIEC, Jean-Pierre, ibid., p. 200.

${ }^{142}$ SEIDL-HOHENVELDERN, Ignaz, ibid., p. 7.
\end{abstract}




\section{Doctrina y Jurisprudencia}

Uma indemnização adequada deve, também tomar em consideração as condições do mercado ("market value" ${ }^{\text {"143) }}$ no país expropriando ou nacionalizando, como refere IGNAZ SEIDL-HOHENVELDERN: "(é) o método mais equitativo de avaliação de danos ..." ${ }^{144}$. Mas do que mercado se trata? Bolsas de valores ou outros? O mercado/bolsas de valores encontra-se, regra geral, nos países desenvolvidos e, nesta situação, as exigências da adequada avaliação resumem-se à que “... as condições do mercado, qual quer que seja, não sejam falseados pelo Estado expropriando ou nacionalizando, de forma a minorar artificialmente os valores da indemnização" ${ }^{145}$. Contudo, o que fazer quando não existe este tipo de mercado o que é o caso de números países em desenvolvimento? Olhando para algumas convenções bilaterais sobre a promoção e protecção recíproca de investimentos celebradas entre países exportadores de capitais e país importadores de capitais, pode-se verificar que o valor da indemnização faz referência ao "mercado do investimento expropriado"146 ou ao "valor justo do mercado do valor do investimento expropriado" ${ }^{147}$. O uso desses termos deixa transparecer uma aproximação flexível do termo "mercado". Com efeito, este pode abranger uma bolsa de valores ou outros mercados que não faz o objecto de uma regulamentação, por exemplo, um hipotético "mercado do investimento". Neste caso, a avaliação do valor do investimento - sem mercado regulamentado - poderá se fazer através de entidades especializadas (empresas de auditorias, empresas de consultorias, etc.). Em todo caso, será o preço do mercado onde o bem foi expropriado ou nacionalizado e não o mercado de um outro país ${ }^{148}$. Regra geral, o preço do mercado deve ser estabelecido no momento da tomada do acto de expropriação ou de nacionalização $^{149}$. Contudo, o anúncio de uma medida de expropriação pode ter por

\footnotetext{
${ }^{143}$ Vide, por exemplo, a sentença arbitral Middle East Shipping and Handling Co. S.A. vs. Arab Republic of Egypt, de 12 de Abril de 2002, op. cit., §. 107, §. 144.

${ }^{144}$ SEIDL-HOHENVELDERN, Ignaz, op. cit., p. 19.

${ }^{145}$ CARREAU, Dominique e JUILLARD, Patrick, op. cit., p. 541.

${ }^{146}$ N. ${ }^{\circ} 1$ do Artigo 4 do Acordo sobre a Promoção e Protecção Recíproca de Investimento entre o Governo da República de Moçambique e o Governo da República da China.

${ }^{147}$ N. ${ }^{\circ} 2$ do Artigo 3 do Tratado entre a República de Moçambique e os Estados Unidos de América sobre a Promoção e Protecção Recíproca de Investimentos.

${ }^{148}$ SEIDL-HOHENVELDERN, Ignaz, "L'évaluation des dommages dans les arbitrages transnationaux", op. cit., p. 17.

${ }^{149}$ Id., ibid.
} 
consequência uma queda do preço do bem visado, assim, não se pode estabelecer o valor no dia da expropriação ou nacionalização mas num período anterior a esta operação. Por exemplo, o n. ${ }^{\circ} 1$ do Artigo 4 do Acordo sobre a Promoção e Protecção Recíproca de Investimento entre o Governo da República de Moçambique e o Governo da República da China prevê que: "Tal compensação deverá ser igual pelo menos ao valor de mercado do investimento expropriado imediatamente antes da expropriação ter sido tornada pública" (o sublinhado é nosso). Do mesmo modo, o n. ${ }^{\circ} 2$ do Artigo 3 do Tratado entre a República de Moçambique e os Estados Unidos de América sobre a Promoção e Protecção Recíproca de Investimento, precisa: "Seja paga uma indemnização sem demora; seja equivalente ao valor justo do mercado do valor do investimento expropriado imediatamente antes do acto de expropriação ("a data de expropriação") ...” (o sublinhado é nosso). O valor no momento da expropriação ou nacionalização é, também, de difícil avaliação quando esta não foi realizada em uma única vez. Por exemplo, no caso de "creeping expropriation”, o dono de uma empresa é sucessivamente privado do poder de direcção e do direito de gozo sobre a mesma; como refere IGNAZ SEIDL-HOHENVELDERN, “Le moment où la nationalisation a eu lieu est le moment où les droits du propriétaire ont cessé d'exister et non pas le moment, où

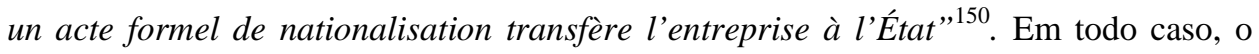
preço do mercado estabelecido no momento da expropriação ou nacionalização deve integrar as consequências da taxa de inflação até o momento do pagamento da indemnização ${ }^{151}$. Apesar do facto de o método do preço do mercado seja o método mais equitativo para avaliar danos, esta não é de aplicação geral; como refere IGNAZ SEIDL-HOHENVELDERN, "Même là où un prix de marché existe, il peut y avoir des cas où il serait inéquitable de l'appliquer. On devrait donc prendre en considération d'autres méthodes d'évaluation pour corriger ce résultat" ${ }^{\prime 152} 153$.

\footnotetext{
${ }^{150}$ Idem, p. 18.

${ }^{151}$ Id., ibid.

${ }^{152}$ Id., ibid.

${ }^{153}$ Na sentença arbitral AMINOIL vários métodos de avaliação foram combinados, HUNTER, Martin, e SINCLAIR, Anthony C., "Aminoil Revisited. Reflections on a Story of Changing Circumstances", op. cit., p. 361ss. Vide, também, sobre a combinação de métodos, LAVIEC, Jean-Pierre, Protection et promotion des investissements. Étude de droit international économique, op. cit., p. 200. Por este autor “... considera-se que é adequada uma indemnização que é só calculada segundo métodos cuja objectividade não pode ser contestada”, ibid., p. 201.
} 


\subsection{Os prazos de pagamento: uma indemnização imediata}

De acordo com o Artigo 5 do Anexo 1: "Os investimentos não serão nacionalizados ou expropriados no território de qualquer Estado Parte, a menos que tais medidas sejam tomadas para fins de utilidade pública, de acordo com o devido processo legal, com base não discriminatória e sujeitas a uma indemnização imediata ..." (o sublinhado é nosso). Esta terminologia é de origem anglo-saxónica ${ }^{154}$. A versão de língua inglesa reflecte muito bem esta, com a noção de "payment of prompt (...) compensation" o que foi traduzida na versão portuguesa por "indemnização imediata". No n. ${ }^{\circ} 1$ do Artigo 3 do Tratado entre a República de Moçambique e os Estados Unidos de América sobre a Promoção e Protecção Recíproca de Investimento, esta palavra foi traduzida não por "imediata" mas por "pronto". Em tudo caso, esta palavra "imediata" não traduz a realidade dos factos. Decorre sempre um determinado prazo entre o momento em que a expropriação ou a nacionalização intervém e o em que o investidor expropriado ou nacionalizado recebe a indemnização. O princípio mais realista na matéria é de considerar que os prazos de pagamento sejam razoáveis, sem que um determinado prazo seja fixado. É a aproximação escolhida pelo Acordo sobre a Promoção e Protecção Recíproca de Investimento entre o Governo da República de Moçambique e o Governo da República da China prevê que: “A compensação deverá incluir os juros à taxa normal do mercado até à data do pagamento, ser feita sem demora, e ser efectivamente realizável" (o sublinhado é nosso). Esta terminologia é mais conforme ao Direito Internacional que nunca requereu o pagamento "imediato" de uma indemnização ${ }^{155}$. Além disso, a experiência da prática demonstra que a celeridade no pagamento da indemnização não é a virtude cardeal do Estado envolvido. É na boa fé na execução do pagamento que reside, por parte, a solução e, mormente, o facto do Estado devedor reconhecer um atraso injustificado. Assim, coloca-se, logicamente, a questão complementar do pagamento de juros no caso em que existe, realmente, um atraso injustificado no pagamento da indemnização. Nesta perspectiva, o n. ${ }^{\circ} 1$ do Artigo 4 do Acordo sobre a Promoção e Protecção Recíproca de Investimento entre o Governo da República de Moçambique e o Governo da República da China prevê que: " $A$ compensação deverá incluir os juros à taxa normal do mercado até à data do

\footnotetext{
154 LAVIEC, Jean-Pierre, Protection et promotion des investissements. Étude de droit international économique, op. cit., p. 206.

${ }^{155}$ SEIDL-HOHENVELDERN, Ignaz, op. cit., p. 18.
} 


\section{Doctrina y Jurisprudencia}

pagamento, ser feita sem demora, e ser efectivamente realizável" (o sublinhado é nosso). É, também, o critério da "taxa comercialmente razoável" que foi escolhido no Tratado entre a República de Moçambique e os Estados Unidos de América sobre a Promoção e Protecção Recíproca de Investimento (n. ${ }^{\circ} 3$ do Artigo 3). Contudo essas opções derrogam aos critérios usuais que optaram para as taxas legais ${ }^{156}$.

\subsection{As modalidades de pagamento: uma indemnização efectiva}

De acordo com o Artigo 5 do Anexo 1: "Os investimentos não serão nacionalizados ou expropriados no território de qualquer Estado Parte, a menos que tais medidas sejam tomadas para fins de utilidade pública, de acordo com o devido processo legal, com base não discriminatória e sujeitas a uma indemnização (...) efectiva" (o sublinhado é nosso). Uma indemnização "efectiva" é aquela que é transferível para o Estado nacional do investidor no caso em que o Estado Acolhedor não pode oferecer possibilidades de reinvestimento aceitáveis ${ }^{157}$. No caso em que a indemnização deve ser transferida no Estado nacional do investidor, os atrasos no pagamento da indemnização devem ser compensados pela taxa de interesse existente neste país ${ }^{158}{ }^{159}$. Para tornar-se a indemnização transferível, o preço do mercado do Estado Acolhedor deve ser convertida na moeda do Estado nacional do investidor. Contudo, algumas convenções bilaterais sobre a promoção e protecção recíproca de investimentos adoptaram medidas mais flexíveis. Por exemplo, o n. ${ }^{\circ} 4$ do Artigo 3 do Tratado entre a República de Moçambique e os Estados Unidos de América sobre a Promoção e Protecção Recíproca de Investimento, dispõe: “Se o valor justo do mercado for expresso em moeda não de circulação, a indemnização paga é convertida numa moeda de pagamento na taxa do câmbio do mercado vigente na data de pagamento ...”

${ }^{156}$ Id., ibid. Vide, Sentença arbitral Middle East Shipping and Handling Co. S.A. vs. Arab Republic of Egypt, de 12 de Abril, de 2002, op. cit., §. 173-175.

157 Id., ibid. Coloca-se, também, na prática, a forma de realização do pagamento da indemnização. Logicamente, esta forma deve revestir um valor económico real e concreto pelo interessado. É sobre nas situações em que o pagamento foi realizado em obrigações do Estado (reconhecido pelo Direito Internacional) que o critério da efectividade da indemnização foi discutido, vide, LAVIEC, Jean-Pierre, op. cit., p. 208.

${ }^{158}$ SEIDL-HOHENVELDERN, Ignaz, op. cit., p. 18.

159 Regra geral, a avaliação é realizada na moeda do Estado expropriante ou nacionalizante. Vide, LAVIEC, Jean-Pierre, op. cit., p. 209. 
(o sublinhado é nosso). É claro que o Estado devedor deve se comprometer a autorizar a transferência da indemnização o que é implícito em algumas convenções bilaterais sobre a promoção e protecção recíproca de investimentos. Por exemplo, no Tratado entre a República de Moçambique e os Estados Unidos de América sobre a Promoção e Protecção Recíproca de Investimento, o n. ${ }^{\circ} 2$ do Artigo 3 do referido Tratado prevê que: “... seja equivalente ao valor justo do mercado do valor do investimento expropriado (...) e seja totalmente (...) transferível” (o sublinhado é nosso).

c) As convenções bilaterais sobre a promoção e protecção do investimento como limitações do princípio de exclusividade estadual

As convenções bilaterais sobre a promoção e protecção recíproca de investimentos podem temperar as restrições impostas pelo direito interno do Estado Acolhedor. Contudo, deve situar-se esses dispositivos no âmbito da posição do Direito Internacional na hierarquia das normas vigente no Estado Acolhedor. Em numerosas situações, as convenções bilaterais sobre a promoção e protecção recíproca de investimentos podem temperar uma legislação interna bastante restritiva consagrando um compromisso, pelo Estado Acolhedor, de conceder as autorizações necessárias. Por exemplo, no Tratado entre a República de Moçambique e os Estados Unidos de América sobre a Promoção e Protecção Recíproca de Investimentos: "Cada Parte deve autorizar que todas as transferências relativas a um investimento coberto por este Tratado sejam feitas livremente e sem demora para dentro e fora do seu território" (n. ${ }^{\circ}$ 1 do Artigo 5) ${ }^{160}$. Pode ocorrer situações em que dúvidas podem surgir sobre a compatibilidade de uma norma de direito interno e a referida disposição. Por exemplo, o n. ${ }^{\circ} 3$ do Artigo 15 da Lei n. ${ }^{\circ}$ 3/93, de 24 de Junho dispõe que: "As transferências do capital reexportável ou do produto de indemnização ou remuneração previstas nos termos do artigo precedente serão efectuadas em prestações escalonadas num período

\footnotetext{
${ }^{160}$ Essas transferências incluem: contribuições de capital, lucros, dividendos, ganhos de capital, e receitas de venda de todo ou parte do investimento ou liquidação total ou parcial do investimento, juros, pagamentos de "royalties" impostos de gestão, assistência técnica e outras cobranças, pagamentos feitos sob contrato, incluindo um acordo de empréstimo; e indemnização dada de acordo com os artigos 3 e 4 e pagamentos resultantes de uma disputa de investimento.
} 
não superior a cinco anos e de forma a evitarem-se perturbações na balança de pagamentos $^{161 \text { ”. }}$

Nesta situação, a questão é de saber se, em algumas circunstâncias ${ }^{162}$, a forma da transferência prevista na lei - "prestações escalonadas" - é compatível com a obrigação de transferir "sem demora" prevista pelo Tratado" ${ }^{163}$. Do mesmo modo, como compatibilizar a decisão do Banco de Moçambique que pode recusar uma autorização para exportação de capitais fundamentada na "situação macroeconómica do país e as condições do mercado cambial" (n. ${ }^{\circ} 4$ do Artigo 55 do Decreto n. ${ }^{\circ}$ 83/2010, de 31 de Dezembro) quando o n. ${ }^{\circ} 4$ do Artigo 5 do Tratado entre a República de Moçambique e os Estados Unidos de América sobre a Promoção e Protecção Recíproca de Investimentos que dispõe: "Não obstante o previsto nos números 1 a 3 deste artigo, uma Parte pode proibir uma transferência através da aplicação equitativa, não discriminatória e de boa-fé das suas leis em relação a:

(a) Falência, insolvência ou protecção do direito de credores;

(b) Emissão, comercialização ou negociação de títulos de seguro;

(c) Ofensas criminais ou penais; ou

(d) Garantia do cumprimento das ordens e decisões em processos adjudicatórios e administrativos"? Como se pode verificar, a "situação macroeconómica do país e as condições do mercado cambial” não constam da lista das proibições de transferência autorizada pelo n. ${ }^{\circ} 4$ do Artigo 5 do Tratado entre a República de Moçambique e os Estados Unidos de América sobre a Promoção e

\footnotetext{
${ }^{161}$ A balança de pagamentos congrega as operações inscritas na balança corrente (a balança corrente congrega as operações inscritas na balança comercial (a balança comercial congrega as importações e as exportações de um determinado país num determinado período), mas as operações ligadas aos serviços e transferências), mas os movimentos de capitais a curto e longo prazo.

162 Por exemplo, será que os pagamentos escalonados num período de cinco anos resultantes de indemnização devida no caso de expropriação ou nacionalização, é compatível com o n. ${ }^{\circ} 1$ do Artigo 5 do Tratado entre a República de Moçambique e os Estados Unidos de América sobre a Promoção e Protecção Recíproca de Investimentos?

163 Algumas convenções bilaterais sobre a promoção e protecção recíproca de investimentos não se pronunciam sobre os prazos dentro dos quais as transferências devem ser realizadas, vide, por exemplo, o Artigo 6 do Acordo sobre a Promoção e Protecção Recíproca de Investimento entre o Governo da República de Moçambique e o Governo da República da China que, apesar do facto de “... garantir aos investidores da outra Parte Contratante a transferência dos seus investimentos e rendimentos tidos no seu território...", não determina nenhum período de tempo dentro do qual essas transferências devem ser realizadas.
} 


\section{Doctrina y Jurisprudencia}

Protecção Recíproca de Investimentos ${ }^{164}$. No caso em que as duas normas são inconciliáveis uma parte da solução reside na determinação da hierarquia entre as normas de direito interno e as regras do Direito Internacional.

\section{B. As recomendações no uso da competência exclusiva do Estado Acolhedor em matéria de determinação do regime jurídico do investimento}

O Anexo 1 consagra inflexões "soft" do poder exclusivo do Estado Acolhedor em matéria de determinação do regime jurídico do investimento. Em particular, essas inflexões manifestam-se no âmbito da "promoção directa negativa" do investimento que visa, principalmente, em desencorajar os Estados Partes em praticar algumas condutas julgadas negativas no âmbito da promoção do investimento.

As áreas apontadas como sensíveis são, principalmente, a saúde, a segurança e o meio ambiente ${ }^{165}$. A ratio do Artigo 13 do Anexo 1 é de encorajar os Estados Partes em lutar eficazmente contra os fenómenos de "dumping social" e de "dumping ecológico" $"$. Com efeito, pode-se dificilmente admitir que numa mesma organização económica regional as escolhas dos operadores económicos sejam ditadas pelas normas sociais menos avançadas no plano do progresso social ou os padrões de defesa do ambiente mais baixos quando o objectivo desta mesma organização é construir uma "Comunidade". Por isso, o Artigo 13 do Anexo 1 recomenda aos Estados Partes de abandonar as práticas baseadas no encorajamento do investimento “... através do relaxamento de medidas internas nas áreas da saúde, da segurança e do meio ambiente e acordar em não renunciar a tais medidas...". A estrutura da referida disposição convencional é, ao mesmo tempo, facultativa e abrangente nas suas perspectivas. É facultativa porque o Artigo 13 apenas estabelece uma recomendação - "encorajar" para os Estados Partes sem a devida obrigatoriedade fonte de responsabilidade. Por

\footnotetext{
${ }^{164}$ A condição imposta pelo n. ${ }^{\circ} 6$ do Artigo 15 da Lei n. ${ }^{\circ}$ 3/93, de 24 de Junho, também. Em todo caso, os Estados Partes sujeitos às obrigações decorrentes do Artigo VIII dos Estatutos do Fundo Monetário Internacional (FMI) não podem restringir as transferências de lucros líquidos, os direitos autorais e os juros de empréstimos, salvo aprovação do FMI (Disponível em: <http://www.imf.org/external/french/pubs/ft/aa/aa.pdf > Acesso em: 19-10-2012). Contudo, nem todos os Estados membros do FMI estão comprometidos pelas obrigações decorrentes do Artigo VIII.

${ }^{165}$ Artigo 13 do Anexo 1 do Protocolo.

166 Sobre todos esses aspectos, cfr., CISTAC, Gilles, "Os problemas da integração jurídica na Comunidade de Desenvolvimento da África Austral”, op. cit., p. 224.
} 


\section{Doctrina y Jurisprudencia}

outras palavras, os Estados Partes são convidados a não encorajar essas práticas. Contudo, a formulação que consta do Artigo 13 é duplamente abrangente. Em primeiro lugar, o "encorajamento" de não relaxar as suas medidas internas nas respectivas áreas abrange, pelo menos, os instrumentos contratuais. Nesta perspectiva, os Estados Partes são convidados a não acordar em renunciar a tais medidas através de contratos celebrados com os investidores o que implica, também, de não consagrar cláusulas de estabilização da legislação, nessas matérias, que poderiam impedir todo progresso qualitativo nessas áreas. Em segundo lugar, a recomendação consagrada ultrapassa os ordenamentos jurídicos internos para atingir a rede de tratados internacionais celebrados pelos respectivos Estados que estabeleceram ou consagraram práticas de "relaxamento". Com efeito, o convite lançado aos Estados Partes é, de uma certa forma, muito ousado porque recomenda de “... derrogar os tratados internacionais que tenham ratificado, ou oferecer-se para renunciar a essas medidas ou, de outro modo, derrogar essas medidas, como um factor de encorajamento para o estabelecimento, aquisição, expansão ou retenção, nos seus territórios, de um investimento" (Artigo 13 in fine). Apesar do facto de não constituir uma norma fixando um comportamento obrigatório para os Estados Partes, o Artigo 13 é não menos uma vitória para os defensores dos princípios ecológicos lato sensu. Em todo caso, a harmonização ou a uniformização das legislações relativas ao regime de investimento, prevista no Artigo 19 do Anexo 1 constitui, igualmente, um meio de combate contra quadros jurídicos laxistas. Com efeito, a instituição de normas jurídicas comuns permite lutar eficazmente contra os fenómenos de "dumping social" e de "dumping ecológico"167.

\section{CONCLUSÃO}

Será que o Anexo 1 do Protocolo contribui, eficazmente, para a criação de uma "zona de investimento" atractiva ou de um "clima de investimento favorável" no seio da SADC?

Em termos de princípios reguladores do regime jurídico dos investimentos, não se pode afirmar que o Anexo 1 traz inovações ou constitui uma mais-valia em relação às normas do Direito Internacional existentes na matéria. O referido Anexo apenas

${ }^{167}$ Id., ibid. 


\section{Doctrina y Jurisprudencia}

consagra normas de Direito Internacional já existentes. Contudo, não se pode considerar que o Anexo 1 é totalmente inútil. A sua utilidade pode surgir no caso em que não existe já uma convenção bilateral sobre a promoção e protecção recíproca de investimentos firmado entre o Estado Acolhedor de investimentos e o Estado nacional do investidor que garante uma melhor protecção do investimento ou na hipótese de ausência de legislação interna em matéria de protecção e promoção do investimento. Em todo caso, seria apenas um vade-mécum de normas já existentes na ordem jurídica internacional.

Nessas condições e tomando sempre como ponto de referência o objectivo de construir uma "Comunidade" integrada, o verdadeiro desafio poderia ser de como elaborar um instrumento verdadeiramente integrado de regulação dos investimentos na SADC para realizar um mercado comum dos investimentos nesta Região?

Aqui, como em outras matérias, levanta-se um problema de método, ou seja, consolida-se o método bilateral, signo do regionalismo de cooperação, o que de novo surge, infelizmente, na recente "Avaliação Documental do Plano Indicativo Estratégico de Desenvolvimento Regional 2005-2010” na qual se preconiza: “... um Quadro Modelo de Tratado de Investimento Bilateral (BIT) da SADC"168 ou adopta-se uma lógica resolutamente integrativa, mais criativa, optando para a elaboração de um verdadeiro "Código Regional do Investimento" inspirando da experiência já existente na Comunidade Económica dos Estados da África do Oeste (CEDEAO) ${ }^{169}$. Contudo, a escolha de uma metodologia apropriada para atingir os objectivos consagrados no Tratado da SADC não depende apenas da lógica jurídica. A história da "Comunidade" comprova que os factores políticos são ainda aqueles que dominam a construção da organização; oxalá que os princípios de "solidariedade", "equilíbrio" e "equidade" previstos no Artigo $4^{\circ}$ do Tratado - prevalecem, por uma vez, sobre o de "igualdade de soberania de todos os Estados Membros" na construção de um verdadeiro Mercado Comum dos Investimentos na SADC!

\footnotetext{
${ }^{168}$ Comunidade de Desenvolvimento da África Austral, Avaliação Documental do Plano Indicativo Estratégico de Desenvolvimento Regional 2005-2010. Relatório Final, aprovado Conselho da SADC em Novembro de 2011, Gaborone, SADC Secretariate, p. 41.

${ }^{169}$ CEDEAO, Vision du Marché Commun des Investissements de la CEDEAO, Abuja, Commission de la CEDEAO, 2009, 99p.
} 